\title{
GARANTIIAS PROCEDIMENTALES CONVERTIDAS EN PAPEL MOJADO: LEGALIDAD DE LOS RECHAZOS EN FRONTERA A LA LUZ DEL CONVENIO EUROPEO DERECHOS HUMANOS
}

\author{
When Procedural Safeguards come to Nought: \\ Legality of Border Push-Backs under the \\ European Convention on Human Rights
}

Juan Jonás de Gil Blanco-Rajoy Universidad Carlos III de Madrid E-mail: juanjgbr@hotmail.com

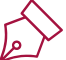

Autor

Los Estados europeos del siglo XXI se enfrentan actualmente a un complejo reto de gestión de flujos migratorios, en muchas ocasiones de carácter mixto, que exige conciliar el respeto por los derechos humanos con la necesidad de mantener la seguridad y controlar la inmigración irregular. Ante esta coyuntura, España, en tanto que frontera sur de la Unión Europea con África, ha adoptado diversos acuerdos y prácticas, incluyendo lo que popularmente se conocen como "devoluciones en caliente", cuyo encaje en la legalidad internacional parece suscitar cierto debate. Así, el presente artículo tiene por objeto estudiar el régimen legal interno que pretende dar cobertura legal a esta práctica, además de cuestionar su legalidad y desmontar la justificación proporcionada por el Gobierno español en este sentido. Asimismo, se analiza en qué medida estos rechazos en frontera suponen la contravención de ciertas normas y principios jurídico-internacionales que vinculan a España en tanto que miembro del Consejo de Europa. Además, se examina la justificación aportada por la Gran Sala del Tribunal Europeo de Derechos Humanos en relación con los rechazos en frontera relativos al caso N. D. y N.T. contra España, así como su trascendencia jurídica. Finalmente, este artículo estudia las implicaciones derivadas de ciertas estrategias de externalización fronteriza respecto de los rechazos en frontera.

European states in the twenty-first century are currently facing a complex challenge with regard to the management of migration flows, which are very often of a bybrid nature. As such, this requires a balance between respect for human rights and the need to maintain security and control irregular migration. Against this backdrop, the Spanish state, as the European Union's southern border with Africa, has adopted several agreements and practices, including what are popularly known as "hot returns", raising the debate over their conformity with international legality. Thus, the aim of this paper is to study the domestic legal regime which intends to provide legal coverage for this practice, as well as question their legality and refute the Spanish government'sjustification in this regard. Furthermore, we analyse the extent to which these cross-

\section{Resumen}


border push-backs violate certain international norms and principles that bind Spain as member of the Council of Europe. Moreover, we examine the justification provided by the Grand Chamber of the European Court of Human Rights in relation to cross-border push-backs regarding the reasoning of N. D. and N. T. v. Spain, as well as its legal significance. Finally, this paper studies the implications derived from certain border externalization strategies with respect to cross-border push-backs.

rechazos en frontera; devoluciones en caliente; migrantes; frontera con Marruecos; derechos humanos; garantías; derecho internacional

cross-border push-backs; hot returns; migrants; border with Morocco; buman rights; guarantees; International Law

Recibido: 07/10/2020. Aceptado: 09/12/2020

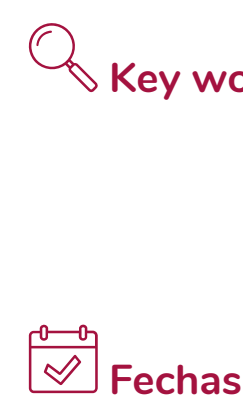

\section{Introducción}

El control de las fronteras exteriores constituye hoy en día un reto sin precedentes al que se enfrentan los Estados del siglo XXI, un reto que se exacerba en el contexto actual donde la globalización y las crecientes oportunidades de movilidad convierten a las migraciones en un proceso inevitable. A mayor abundamiento, las crisis migratorias ${ }^{1}$ que está viviendo Europa dificultan más aún la gestión de los flujos migratorios y este control fronterizo. A la vista de estas circunstancias, han surgido distintas estrategias que la Unión Europea (en adelante, "UE") y sus Estados miembros han adoptado con el objeto de controlar más eficientemente la inmigración, pudiendo destacar, a nivel comunitario, el acuerdo entre la UE y Turquía del 20 marzo de 2016, relativo a la gestión migratoria en el marco de los influjos masivos de refugiados desplazados por mor del conflicto sirio.

La magnitud de este reto migratorio se aprecia de forma especial en las fronteras del Estado español, en tanto que frontera sur de la Unión Europea con el continente africano por vía terrestre. No cabe negar de forma alguna la situación que se vive en ocasiones en las fronteras de Ceuta y Melilla, donde se alcanza por momentos una cierta perturbación del orden público, debido particularmente a los asaltos masivos que se producen en las vallas de estas dos ciudades. De forma significativa, los controles fronterizos de las dos ciudades autónomas no se rigen de acuerdo con el régimen general de la Unión Europea ${ }^{2}$.

1 Conviene de antemano clarificar que con el término "crisis migratorias" estamos aludiendo a crisis protagonizadas por grupos humanos de carácter mixto, esto es, por migrantes stricto sensu y por solicitantes de asilo (y potenciales refugiados) y de protección internacional subsidiaria que, en muchas ocasiones, utilizan las mismas rutas de desplazamiento (González Vega, 2015, p. 188). Esto puede plantear dificultades a la hora de abordar el fenómeno migratorio debido al diferente estatuto jurídico que le corresponde a cada grupo de individuos afectados por dichas crisis.

2 Ello es así desde la firma del acuerdo entre la Unión y el Estado español, en virtud de la adhesión de este último al Convenio de Aplicación del Acuerdo Schengen de 1985 (BOE núm. 81, de 5 de abril de 1994. Corrección de erratas en $B O E$ núm. 85, de 9 de abril). Esta excepción está además recogida en el Reglamento 562/2006 CE, de 
Si bien es evidente la necesidad de gestionar las fronteras exteriores de forma ordenada y eficaz, habida cuenta de la necesidad de controlar la inmigración irregular y de luchar contra las mafias transfronterizas, no es menos cierto que dicha gestión debe en todo momento garantizar el debido respeto a los derechos humanos ${ }^{3}$, pues la transversalidad de estos debe informar constantemente el diseño y la implementación de todas las políticas públicas del Estado.

A este respecto, una “estrategia” adoptada por el Gobierno español en lo referente al control fronterizo es lo que popularmente se conoce como "devoluciones en caliente”. Esta práctica, cuyo régimen y características estudiaremos ut infra, supone en líneas generales la expulsión de territorio español de un migrante que se encuentra en la zona fronteriza, prescindiendo de todo procedimiento administrativo de identificación o audiencia al interesado. Así, a priori y con esta información en mente, suscita ciertas dudas en qué medida estas prácticas tienen encaje en la legalidad internacional, especialmente a la luz del derecho internacional y regional de los derechos humanos.

Partiendo de esta premisa, este artículo pretende analizar en qué consisten los rechazos en frontera, cuestionar la normativa que pretende dotarlos de amparo legal y estudiar en qué medida contravienen lo dispuesto en el Convenio Europeo de Derechos Humanos (en adelante, "CEDH"). Asimismo, se examina la justificación aportada por el Tribunal de Estrasburgo en el caso N. D. y N.T c. España, además de reflexionar acerca de la incidencia de los derechos humanos en la gestión y el control de fronteras.

\section{Rechazos en frontera: definición y contexto}

Si bien son varios los nombres que reciben este tipo de prácticas, tales como "rechazos en frontera" o "expulsiones sumarias", las popularmente denominadas "devoluciones en caliente" son definidas por la doctrina como "la actuación de las Fuerzas y Cuerpos de Seguridad del Estado consistente en la entrega a las autoridades marroquíes por vía de hecho de ciudadanos extranjeros que han sido interceptados por dichos Cuerpos y Fuerzas de Seguridad del Estado en zona de soberanía española sin seguir el procedimiento establecido legalmente ni cumplir las garantías internacionalmente reconocidas" (Martínez Escamilla et al., 2014, p. 2).

Desde que comenzaron las primeras de estas expulsiones en el año 2005 en la frontera entre España y Marruecos, esta práctica no ha cesado (Soler García, 2018, p. 110).

Tal y como examinaremos detalladamente más adelante, tanto el Consejo de Europa como la Organización de las Naciones Unidas han denunciado este tipo de prácticas. No obstante, no ha sido hasta el año 2017 cuando se ha planteado ante el Tribunal Europeo de Derechos Humanos (en adelante, "TEDH”) el primer caso cuestionando la legalidad de las devoluciones en caliente en la frontera hispano-marroquí, el conocido como N. D. y N.Tc. España. En

15 de marzo, sobre el código comunitario de normas para el cruce de personas por las fronteras, también conocido como Código de fronteras Schengen (Diario Oficial de la Unión Europea L 105/1, de 13 de abril de 2006) (Ruiz Sutil, 2016, p. 329).

3 En sentido equivalente se pronunció el Tribunal Europeo de Derechos Humanos en el caso Amuurc. Francia (sentencia (Sala) sobre el asunto Amuur c. Francia, de 25 de junio de 1996 (demanda n.o 19776/92)), en donde el Tribunal afirmó que el control fronterizo debe en todo caso garantizar el respeto de lo dispuesto en el Convenio Europeo de Derechos Humanos (párr. 41). 
relación con los hechos del caso, un grupo de extranjeros intentaron superar el 13 de agosto de 2014 la valla que separa Melilla de Marruecos, entre los cuales se encontraban los demandantes, un ciudadano maliense y otro marfileño que, con ayuda de las autoridades españolas, consiguieron finalmente poner pie en territorio español. No obstante, en ese mismo momento fueron automáticamente esposados y devueltos a Marruecos, sin ningún tipo de garantía procesal ni incoación de procedimiento alguno de identificación. Si bien el Tribunal concluyó en primera instancia ${ }^{4}$ que los rechazos en frontera eran contrarios al Convenio, examinaremos más adelante el cambio jurisprudencial que ha supuesto el fallo de la Gran Sala del TEDH en relación con el mismo caso ${ }^{5}$.

\section{3. "Cobertura legal" en España: la reforma de la LOEx}

En el año 2015, la Ley Orgánica 4/2000, de 11 de enero, sobre derechos y libertades de los extranjeros en España y su integración social ${ }^{6}$ (en adelante, "LOEx"), fue modificada, por iniciativa del Grupo Parlamentario Popular, a través de una enmienda al Proyecto de la Ley Orgánica 4/2015, de 30 de marzo, de protección de la seguridad ciudadana. Sin perjuicio de la dudosa legitimidad con la que el procedimiento legislativo fue llevado a cabo ${ }^{7}$, dicha modificación supone la adición de una Disposición adicional décima (en adelante, “DAD”) titulada “régimen especial de Ceuta y Melilla” (Espiniella Menéndez, 2016, p. 321).

Dicha disposición reza lo siguiente:

1. Los extranjeros que sean detectados en la línea fronteriza de la demarcación territorial de Ceuta o Melilla mientras intentan superar los elementos de contención fronterizos para cruzar irregularmente la frontera podrán ser rechazados a fin de impedir su entrada ilegal en España.

2. En todo caso, el rechazo se realizará respetando la normativa internacional de derechos humanos y de protección internacional de la que España es parte.

3. Las solicitudes de protección internacional se formalizarán en los lugares habilitados al efecto en los pasos fronterizos y se tramitarán conforme a lo establecido en la normativa en materia de protección internacional.

Con anterioridad a esta reforma, la expulsión de extranjeros se regía exclusivamente por tres procedimientos: el recogido en el art. 57 LOEx, relativo a la medida de expulsión; el recogido

4 Sentencia del TEDH (Sección tercera) sobre el asunto N. D. y N. T. contra España, del 3 de octubre de 2017 (demandas n.o 8675/15 y 8697/15).

5 Sentencia del TEDH (Gran Sala) sobre el asunto N. D. y N. T. contra España, del 13 de febrero de 2020 (demandas n.o 8675/15 y 8697/15).

$6 B O E$ n.o 10 , de 12 de enero de 2000.

7 A este respecto, vid. Martínez Escamilla et al., 2014, pp. 7-9. En líneas generales, la cuestionabilidad en la tramitación de esta modificación reside en la elusión de los correspondientes dictámenes preceptivos, así como en la exclusión de la sociedad civil en torno a la posibilidad de pronunciarse en el debate sobre la materia (Soler García, 2018, p. 111). 
en el art. 58 de la misma ley, sobre la devolución; y el recogido en el art. 69, relativo a la denegación de entrada ${ }^{8}$.

Sin embargo, tal y como hemos señalado anteriormente, los rechazos en frontera se venían realizando con anterioridad a esta modificación, sobre todo durante los años 2013 y 2014 . El propio ministro de Interior en el año 2014, Jorge Fernández Díaz, declaró que las “expulsiones en frontera” cumplían en todo caso con lo previsto en la legislación de extranjería ("Fernández Díaz: 'no hay devoluciones en caliente”, 2014).

Con esto en mente, cabe preguntarse entonces: ¿en qué medida resulta necesario establecer una regulación para una práctica que, de acuerdo con el Ministerio, ya gozaba de fundamentación jurídica?

Desde nuestro punto de vista, la promulgación de esta nueva regulación debería entenderse como un reconocimiento tácito de que los rechazos que se venían realizando no gozaban del debido sustento legal. El Acuerdo entre el Reino de España y el Reino de Marruecos, sobre la circulación de personas, el tránsito y la readmisión de extranjeros entrados ilegalmente, era invocado en un intento de justificar estas prácticas. Este acuerdo había sido firmado el 13 de febrero de 1992, comenzando su vigencia el 21 de octubre de $2012^{9}$, si bien se empezó a aplicar de forma provisional desde el año de su firma ${ }^{10}$. No obstante, no habían sido pocas las voces que antes de 2015 habían denunciado la falta de cobertura legal para los rechazos en frontera por diversas razones. Por un lado, debido a que el mencionado acuerdo no hace referencia al procedimiento de toma de decisiones en este campo. Por otro lado, y siendo este punto más significativo, debido al hecho de que dicho acuerdo, en su artículo segundo, impone diversas obligaciones internacionales para ambas partes, como la documentación de forma escrita del acto de entrega y la identificación de los individuos objeto de entrega (Espiniella Menéndez, 2016, p. 322).

De esta forma, a fin de comprender mejor las implicaciones del precepto en cuestión de la LOEx, resulta interesante realizar un análisis comparativo de este régimen especial con el procedimiento ordinario de devolución, particularmente desde el punto de vista de la legalidad prevista por nuestro ordenamiento jurídico.

El régimen de la DAD se aplica, de acuerdo con el primer apartado, únicamente a "extranjeros que sean detectados en la línea fronteriza de la demarcación territorial de Ceuta o Melilla mientras intentan superar los elementos de contención fronterizos". Así, atendiendo a la dicción literal de este precepto, la norma no resulta de aplicación a los extranjeros que hayan rebasado los elementos de contención fronterizos y se hayan apeado enteramente de la valla fronteriza, puesto que, en tal caso, la acción contemplada por la norma ("mientras intentan superar") ha finalizado, y en dicho supuesto la devolución afectaría a un individuo que ha rebasado la línea fronteriza, y que se halla, por tanto, en suelo español. De la misma forma, este régimen no resulta de aplicación para extranjeros que hayan accedido de forma irregular a territorio español vía marítima, dada la ausencia de elementos de contención fronterizos (Espiniella Menéndez, 2016, p. 323). 
Así, la aplicación de este régimen supone un rechazo inmediato de la persona interceptada para así imposibilitar su entrada en suelo español.

No obstante, resulta más destacable la comparación de elementos propios del procedimiento ordinario de devolución y sus correspondientes garantías jurídicas, que parecen no estar presentes en los rechazos en frontera. De acuerdo con el art. 23.2 del Reglamento de la Ley Orgánica 4/2000, sobre derechos y libertades de los extranjeros en España y su integración social ${ }^{11}$ (en adelante, "RLOEx"), precepto referido al procedimiento de devolución ordinaria, las Fuerzas y Cuerpos de Seguridad del Estado que se encargan de la custodia de fronteras y costas, en caso de interceptación de extranjeros, tienen el deber de "conducirles con la mayor brevedad posible a la comisaría correspondiente del Cuerpo Nacional de Policía”. Una vez allí, los extranjeros son identificados y, en su caso, se procede a su devolución. Resulta evidente que nada de lo expuesto se contempla en la DAD de la LOEx. En su lugar, con dicha disposición se pretende dotar de cobertura legal a una vía de hecho consistente en devolver a personas que se encuentran en la línea fronteriza de forma automática e inmediata.

Resulta conveniente, si cabe, referirnos a la precisión que realiza la disposición en relación con las solicitudes de protección internacional, que deberán formalizarse en los "lugares habilitados al efecto en los pasos fronterizos". Son muchas las dudas que surgen sobre quiénes serán conducidos a dichos lugares, toda vez que, en el proceso de rechazo automático, y dada la dicción literal de la disposición, no parece que se puedan dar las condiciones para presentar una solicitud. También resulta cuestionable la ausencia de referencia alguna a las condiciones materiales que deben presentar dichos lugares habilitados, lo que contrasta sobremanera con lo dispuesto en el art. 15.4 RLOEx sobre las condiciones que deben reunir las instalaciones a las que son conducidos los extranjeros en el contexto de una denegación de entrada por puesto habilitado, tales como la dotación de unos mínimos servicios adecuados, incluyendo servicios sanitarios, sociales y jurídicos, debiendo estos ser acordes al volumen medio de ocupación. Así, parece evidente que la DAD referida a las devoluciones sumarias adolece de una ambigüedad y vaguedad que choca indudablemente con la concreción y claridad del régimen relativo al procedimiento de devolución ordinario.

Por otro lado, resulta interesante referirnos a la sistematicidad de esta norma, en comparación con el procedimiento ordinario de devolución. A diferencia de este último, donde, a tenor de lo dispuesto en el art. 58.5 LOEx y en el art. 23.4 RLOEx, interviene el subdelegado de Gobierno o el delegado en las comunidades de una sola provincia, el régimen referido a las devoluciones sumarias no prevé la existencia de un órgano que acuerde el rechazo en cuestión. Asimismo, en contraste con lo previsto en el art. 15.1 RLOEx, relativo a la denegación de entrada, no se observa en la $\mathrm{DAD}$ ninguna exigencia en relación con una resolución motivada que sea notificada y que contenga información sobre posibles recursos y sus correspondientes plazos. De igual manera, el régimen de las devoluciones sumarias, a diferencia de lo dispuesto sobre la devolución ordinaria, no prevé la posibilidad de solicitar a la autoridad judicial la adopción de medidas de internamiento, en virtud de lo establecido en el art. 58.6 LOEx y el art. 23.4 RLOEx, de la misma forma que tampoco recoge nada relacionado con la comunicación al consulado o a la embajada del país de origen como dispone el art. 15.6 RLOEx. Tampoco se hace referencia alguna en la $\mathrm{DAD}$ a la posibilidad que tiene el extranjero en la denegación de entrada por puesto habilitado de acogerse a la protección jurisdiccional, en virtud de la cual

11 BOE n.․ 103, de 30 de abril de 2011. 
el interesado puede interponer recurso contencioso-administrativo y exigir que se deje constancia en acta de dicha voluntad, la cual se incorporará al expediente, lo que le permitirá acogerse también a la asistencia jurídica gratuita, en virtud de lo dispuesto en los arts. 15.2 y 23.4 RLOEx. Otra diferencia entre los dos procedimientos estriba en que el de devolución ordinaria contempla la posibilidad de interponer recurso administrativo y jurisdiccional mediante una representación diplomática o consular, tal y como dispone el art. 15.7 RLOEx. Resulta evidente, pues, cómo el rechazo en frontera regulado en la DAD suscita razonables dudas en torno al respeto y al alcance de la audiencia a la que tiene derecho el interesado, los plazos que rigen, la prestación de asistencia por un intérprete y letrado o el sometimiento de la actuación administrativa a un mínimo control jurisdiccional.

Asimismo, el régimen de las devoluciones en caliente no contiene nada sobre la posibilidad de suspender la ejecución del rechazo en frontera, exceptuando la que se derivaría de la formalización de una solicitud de protección internacional; solicitud que, como hemos comprobado, no tiene mucha cabida en el contexto de una expulsión de este tipo. De esta forma, ninguno de los preceptos de la DAD se refiere a la posibilidad de suspender el rechazo de una persona que padezca una enfermedad y cuya devolución pueda suponer una puesta en peligro de su salud, ni de una mujer embarazada que pueda verse afectada como consecuencia de la devolución. Si bien cabe reconocer que el perfil de estas personas puede no coincidir con el grueso de los inmigrantes que intentan acceder a territorio español de esta forma, sí debe ser señalada la ausencia de dicha regulación, en la medida en que sí que está presente en el régimen previsto para el procedimiento ordinario de devolución, a tenor de lo dispuesto en el art. 58.4 LOEx y el art. 23.6 RLOEx. De igual forma, el régimen de las devoluciones sumarias no recoge nada en relación con los menores extranjeros no acompañados y su identificación. Así, resulta cuestionable hasta qué punto dicho régimen establece las garantías mínimas de protección previstas en el Protocolo Marco relativo a ciertas actuaciones respecto de los menores extranjeros no acompañados ${ }^{12}$ (Espiniella Menéndez, 2016, p. 326).

Con esta comparativa en mente, resulta interesante finalizar este análisis adoptando la perspectiva del ordenamiento jurídico interno y preguntándose acerca de la constitucionalidad de la disposición en cuestión, particularmente en lo referente al derecho a acceder a la justicia y a la legalidad de la actuación de la Administración.

En relación con esta última cuestión, la $\mathrm{DAD}$ nos permitiría hablar de una cierta vulneración del art. 105.c) de la Constitución española ${ }^{13}$, en la medida en que ampara una vía de hecho. Atendiendo a la literalidad del precepto de la LOEx, no existe una regulación mínima del procedimiento mediante el cual se materializan los actos administrativos, de acuerdo con las exigencias de la Constitución, de la misma forma que tampoco se regula el procedimiento que garantice la audiencia al interesado, en caso de que esta sea necesaria. Además, la regulación sobre rechazos en frontera difiere sustantivamente en cuanto al derecho a la asistencia jurídi-

12 Este protocolo, creado por mandato del art. 190.2 RLOEx, fue aprobado mediante la Resolución de 13 de octubre de 2014, de la Subsecretaría, por la que se publica el Acuerdo para la aprobación del Protocolo Marco sobre determinadas actuaciones en relación con los menores extranjeros no acompañados ( $B O E$ n.․2 251, de 16 de octubre de 2014). Este Protocolo desarrolla las previsiones del art. 190 RLOEx, siendo destacables como garantías previstas la intervención del Servicio Público de protección de menores y el derecho a ser informado sobre la protección internacional y, en su caso, a solicitarla. 
ca gratuita previsto en el procedimiento de devolución, de acuerdo con el art. 23.3 RLOEx, en caso de que el interesado no dispusiera de los recursos económicos necesarios. Así, la vía de hecho amparada por la DAD supone la conculcación de principios recogidos en el apartado tercero del art. 9 de la Constitución, de un carácter sumamente elemental, incluyendo el principio de seguridad jurídica, legalidad e interdicción de la arbitrariedad de los poderes públicos. Resulta especialmente destacable también la imprecisión y ambigüedad de la que adolece el término "podrán ser rechazados", especialmente en lo referente a la determinación del modo, los medios y el cuándo, lo que puede comprometer la protección e incluso el derecho fundamental a la vida - consagrado en el art. 15 de la Constitución- de ciertos grupos de personas, como menores, o aquellos necesitados de asistencia sanitaria debido a un accidente o enfermedad grave.

En relación con la cuestión del acceso a la justicia, la $\mathrm{DAD}$ permite cuestionar la materialización del derecho a la tutela judicial efectiva y del derecho a la asistencia y defensa jurídica, de acuerdo con lo establecido en el art. 24 de la Constitución. Atendiendo a la jurisprudencia española en esta materia, concretamente la sentencia del Tribunal Constitucional (en adelante, "STC") 95/2003, de 22 de mayo, y la STC 236/2007, de 7 de noviembre, el derecho mencionado constituye un derecho fundamental, inherente a toda persona, que no atiende al status o a la regularidad de la situación del extranjero. A mayor abundamiento, la limitación de este derecho ni siquiera cumple con los requisitos dispuestos en la Constitución a tal efecto, es decir, el respeto al contenido esencial de un derecho de ese carácter y la reserva de ley. Finalmente, conviene señalar la posible conculcación del art. 106 de la Constitución, en la medida en que los tribunales no pueden controlar la legalidad de los actos administrativos derivados de la actuación en cuestión, ni tampoco controlar el sometimiento de dichos actos a los fines que le son propios.

Así, dadas las conclusiones de este análisis, no sorprende el hecho de que el Alto Comisionado de las Naciones Unidas para los Refugiados (en adelante, “ACNUR”) haya recomendado la incoación de un procedimiento mediante el cual se desarrolle de forma reglamentaria la disposición adicional de la LOEx, con el objeto de que el extranjero pueda disfrutar de las garantías procesales que le corresponden (Ruiz Sutil, 2016, p. 332). De la misma forma, tampoco choca el hecho de que más de cincuenta diputados pertenecientes a distintos grupos del hemiciclo presentaran un recurso de inconstitucionalidad contra la Ley de Seguridad Ciudadana, pese a que finalmente el Tribunal Constitucional haya avalado la modificación mediante la cual se introduce la $\mathrm{DAD}^{14}$.

14 En el momento en el que se escriben estas líneas - noviembre del 2020 - no conocemos el contenido íntegro de la sentencia al respecto. Sin embargo, la nota informativa emitida por el Tribunal Constitucional señala que "El régimen especial para Ceuta y Melilla de rechazo en frontera de los extranjeros que intenten entrar ilegalmente (Disposición Final Primera LOPSC), es conforme a la doctrina del Tribunal Europeo de Derechos Humanos". Además, se dice que "el rechazo ha de llevarse a cabo con las garantías que a las personas extranjeras reconocen las normas, acuerdos y tratados internacionales ratificados por Espańa, debiendo ser reales y efectivos los procedimientos de entrada legal en territorio espańol. En todo caso, los cuerpos y fuerzas de seguridad deberán prestar especial atención a las categorías de personas especialmente vulnerables (los menores de edad, las embarazadas o personas de edad avanzada)" (Tribunal Constitucional, 2020, p. 2). 


\subsection{Justificación del Gobierno español mediante la frontera "operativa": un concepto jurídicamente insostenible}

A fin de "justificar” este tipo de prácticas, el Ministerio de Interior se ha basado en distintos argumentos para argüir que las devoluciones sumarias gozan de cobertura legal. Si bien el presente artículo no tiene por objeto examinar todas las argumentaciones mencionadas, sí resulta interesante, desde nuestro punto de vista, analizar la que ha sido formulada ante el TEDH por el Gobierno español con el objeto de justificar las devoluciones en caliente relativas al caso $N$. D. y N. T. que, en último término, como veremos, adolecen de una evidente inadmisibilidad jurídica.

Este intento de justificación al que nos referimos se basa en la idea de que los rechazos en frontera suponen la denegación de entrada a personas que, pese a estar intentando acceder a territorio español prescindiendo de los puestos habilitados al efecto, finalmente no han llegado a acceder a dicho territorio, basándose en lo que se denomina un concepto "operativo" de frontera.

El 8 de febrero de 2014, la Dirección Adjunta Operativa de la Guardia Civil emitió un informe cuyo destinatario era su director general, que se refería a los hechos ocurridos el 6 de febrero de 2014 en la frontera de Ceuta, siendo posteriormente remitido al Congreso de los Diputados por el Ministerio de Interior el 7 de marzo de 2014. El informe analiza tres casos donde, actuando la Guardia Civil en el contexto de tentativas de acceso al territorio español a través de puestos no habilitados en la frontera con Marruecos, sería de aplicación un concepto "operativo" de frontera, distinto de su significado tradicional. En relación con nuestro estudio, nos preocupa uno de los supuestos, donde se afirma que "la valla interna materializa la línea con la que el Estado, en una decisión libre y soberana, delimita, a los solos efectos del régimen de extranjería, el territorio nacional” (Martínez Escamilla y Sánchez Tomás, 2015, p. 8). Así, se consideraría que un inmigrante ha alcanzado el territorio español, quedando sujeto al régimen de extranjería, una vez ha rebasado la valla interna ${ }^{15}$. De esta forma, el Gobierno pretende justificar este tipo de actuaciones contra inmigrantes que, por ejemplo, una vez superada la valla externa, permanecen atrapados en el entramado de la sirga tridimensional sin poder saltar la valla interior.

No obstante, resulta necesario examinar el fundamento jurídico de este planteamiento. En primer lugar, la doble valla originaria, presente tanto en Ceuta como en Melilla, forma parte del territorio nacional (Acosta Sánchez, 2014, p. 26). Por ende, desde una perspectiva jurídica, no cabe argumentar que la zona que se encuentra entre las dos vallas no forma parte del territorio español. En este sentido, tanto el Gobierno Socialista del año 2005 como el Popular de 2014 han defendido que al espacio que separa las dos vallas no le sería de aplicación la legislación de extranjería, diferenciando así entre la frontera política, que tendría prioridad, de la frontera topográfica o geográfica. De acuerdo con ambos Gobiernos, la aplicación del concepto de frontera geográfica implicaría reconocer el acceso a territorio español una vez que

15 La frontera con Marruecos está conformada de forma diferente en Ceuta y en Melilla. En esta última, la demarcación territorial actual se compone de dos vallas construidas en 1998, a las que se añadió entre ellas una sirga tridimensional en 2005 (Acosta Sánchez, 2014, p. 18). Por otro lado, la frontera de Ceuta con Marruecos está conformada por dos vallas, con una altura de seis metros, entre las cuales se encuentra una carretera asfaltada de 3,5 metros de anchura (González Sacaluga, 2017, p. 44). 
el inmigrante ha superado la verja militar previa a la valla exterior ${ }^{16}$, lo que constituye una interpretación que califican de "insostenible” (Acosta Sánchez, 2014, p. 27).

Así, las implicaciones que se derivan de esto no son baladíes. La aplicación de este concepto “operativo" de frontera supone virtualmente la retrotracción unilateral de la frontera con el objeto de inaplicar la legislación en materia de extranjería. Y es que el entonces ministro Fernández Díaz afirmó en 2014 que este concepto de frontera operativa "se efectúa en Ceuta y Melilla precisamente porque Ceuta y Melilla tienen unas características que no tiene ningún otro perímetro fronterizo, y es evidente que esa singularidad, esa especificidad debe ser tenida en cuenta a la hora de desarrollar operativamente el cumplimiento de la legalidad. No se puede pretender aplicar la ley de la misma forma en Ceuta y Melilla que en otros lugares que no tienen nada que ver" (Acosta Sánchez, 2014, p. 28). Por tanto, el concepto “operativo” de frontera implica una determinación de la frontera ad casu, de la que se deriva una evidente arbitrariedad que vulnera el principio de seguridad jurídica consagrado en el art. 9.3 de nuestra Carta Magna y el principio de igualdad, vulneración que el entonces ministro de Interior parece estar avalando. En este sentido, conviene destacar el Informe del Defensor del Pueblo del año 2005, en el que se mantiene que la Administración no es competente para establecer a partir de dónde rige la ley española, y que no cabe la inaplicación de la legislación española sobre una determinada parte del territorio español. Concluye dicho informe con que, a efectos de entrada en territorio español, se considerará que una persona se encuentra en el mismo una vez haya traspasado los límites que han sido impuestos internacionalmente, siendo aplicable a partir de entonces la legislación española (Martínez Escamilla y Sánchez Tomás, 2015, p. 10).

Teniendo en cuenta que las fronteras han sido establecidas por normas internacionales, la utilización del concepto "operativo" de frontera supone excepcionar la aplicación de un tratado internacional ${ }^{17}$, con base en una supuesta singularidad a nivel fronterizo y geográfico de Ceuta y Melilla, que además pretende justificar una regulación propia a nivel doméstico.

No obstante, aunque se le confiriera una mínima admisibilidad a la idea de la "frontera operativa", la actuación de la Administración en el contexto de los rechazos en frontera se vería de todas formas vinculada por el ordenamiento interno, en la medida en que las actuaciones realizadas por miembros de la Administración en el desempeño de sus respectivos cargos está siempre sometida al imperio de la ley, con independencia de que dicha actividad tenga lugar en una zona perteneciente al territorio nacional o no, según ha establecido el Tribunal Constitucional en la STC 21/1997, de 10 de febrero (FJ 2), y el TEDH, tal y como examinaremos ut infra.

De esta forma, independientemente de la delimitación del territorio nacional y su frontera, es evidente que, las Fuerzas y Cuerpos de Seguridad del Estado, actuando sobre personas extranjeras, se encuentren fuera o dentro de territorio español, están operando en el ejercicio de sus funciones y en calidad de agentes y funcionarios públicos. Así, no cabe negar el sometimiento

16 Con anterioridad a la construcción del doble vallado, existía una verja militar, de la cual quedan ciertos restos actualmente, que a finales de los años noventa se reveló como ineficiente en tanto que elemento disuasivo (Acosta Sánchez, 2014, p. 19).

17 Conviene señalar que la invocación del derecho interno como justificación del incumplimiento de una norma o tratado internacional convencional contraviene lo dispuesto en el art. 27 del Convenio de Viena sobre el Derecho de los Tratados, adoptado en Viena el 23 de mayo de 1969, al que España se adhirió el 2 de mayo de 1972 (BOE n.o 142, de 13 de junio de 1980). 
de dicha actividad al cumplimiento del ordenamiento jurídico doméstico y especialmente, a la Constitución.

Por tanto, no cabe sino concluir que el concepto "operativo" de frontera del que se ha valido el Ejecutivo español en orden a dotar de cobertura legal a las devoluciones sumarias resulta sin lugar a dudas jurídicamente inadmisible.

\section{Incidencia de los rechazos en frontera en el marco jurídico en materia de derechos humanos}

El objeto de este apartado es analizar de qué forma los rechazos contemplados en la DAD contravienen obligaciones jurídico-internacionales que vinculan a España en virtud de su condición de miembro del Consejo de Europa y de su adhesión al CEDH, al que se adhirió el 24 de noviembre de $1977^{18}$. Así, el acervo jurídico a tener en cuenta va a ser el marco regional de derechos humanos consagrado en el CEDH, por cuanto nos permitirá contrastar su análisis con el razonamiento presentado por la Gran Sala del TEDH en el caso N. D. y N. T. contra España.

\subsection{Prohibición de tortura}

Recogida en el art. $3 \mathrm{CEDH}$, supone esta prohibición que "Nadie podrá ser sometido a tortura ni a penas o tratos inhumanos o degradantes”. En este sentido, la jurisprudencia del TEDH resulta clave en orden a determinar y entender la trascendencia y el alcance de esta prohibición en relación con los rechazos en frontera.

Por lo que respecta a la práctica objeto de estudio, el TEDH estableció en el asunto Cruz Varas yotros c. Suecia ${ }^{19}$ que esta prohibición resulta aplicable a expulsiones y devoluciones (párr. 70).

Dicha prohibición desencadena la responsabilidad del Estado en base a la cual las autoridades públicas deben asegurarse de que el individuo en cuestión, en caso de ser repatriado, no correrá "un riesgo auténtico de ser sometido a tratos contrarios al artículo 3" ${ }^{20}$, según ha establecido el TEDH en numerosos asuntos, tales como Hirsi Jamaa y otros c. Italia ${ }^{21}$ (en adelante, “Hirsi Jamaa”) (párr. 146), Salab Sheekh c. Paises Bajos"22 (párr. 123), Hilal c. Reino Unido 23

18 Instrumento de Ratificación del Convenio para la Protección de los Derechos Humanos y de las Libertades Fundamentales, hecho en Roma el 4 de noviembre de 1950, y enmendado por los Protocolos adicionales números 3 y 5, de 6 de mayo de 1963 y 20 de enero de 1966, respectivamente (BOE n.o 243, de 10 de octubre de 1979 , pp. 23564-23570).

19 Sentencia del TEDH sobre el asunto Cruz Varas y otros c. Suecia, de 20 de marzo de 1991 (demanda n.o 46/1990/237/307).

20 Esta prohibición resulta igualmente aplicable a supuestos de refoulement indirecto (Hirsi Jamaa y otros c. Italia, párr. 146). Al respecto, vid. nota 36.

21 Sentencia del TEDH (Gran Sala) sobre el asunto Hirsi Jamaa y otros c. Italia, de 23 de febrero de 2012 (demanda n. $27765 / 09)$.

22 Sentencia del TEDH (Sección tercera) sobre el asunto Salab Sheekh c. Países Bajos, de 11 de enero de 2007 (demanda n.o 1948/04). 
(párr. 59) y Abmed c. Austria ${ }^{24}$ (en adelante, “Abmed”) (párrs. 38-41) ${ }^{25}$. Asimismo, precisa el Tribunal que el Estado que lleva a cabo la expulsión debe asegurarse de que el país al que es expulsado el individuo está dotado de las garantías necesarias que permitan concluir que llevará a cabo un debido análisis de potenciales riesgos, antes de proceder a la devolución a su país de origen, tal y como dictaminó el TEDH en el asunto Hirsi Jamaa (párr. 147). Además, el alcance de este artículo en el contexto de expulsiones es de tal magnitud que el TEDH ha precisado que la prohibición se debe respetar independientemente de las actividades del individuo en cuestión, "however undesirable or dangerous", según estableció el TEDH en el asunto Abmed (párrs. 40-41). A mayor abundamiento, el carácter absoluto de esta prohibición se deduce de su vigencia incluso en un contexto de guerra o de emergencia nacional, tal y como se estableció en el asunto Soering c. Reino Unido ${ }^{26}$ (en adelante, "Soering") (párr. 88).

De esta forma, procede examinar si España cumple con el deber ligado a la prohibición de tortura, con base en el cual, al expulsar de forma sumaria a extranjeros, se asegura de que no existen riesgos de que los mismos vayan a ser sometidos a tratos contrarios al art. 3 CEDH. En primer lugar, resulta evidente que en el marco de un rechazo en frontera, no tiene ninguna cabida un proceso individualizado de audiencia al interesado en el cual este pueda exponer su situación y realizar alegación pertinente en lo referente a su seguridad y motivos de su desplazamiento. Sin perjuicio del contexto concreto ligado al caso objeto de análisis, resulta muy cuestionable el cumplimiento de este deber por parte del Estado español, en la medida en que son muy numerosos los informes emitidos por la sociedad civil y diversas organizaciones no gubernamentales y organizaciones internacionales de derechos humanos, en los que se han denunciado las torturas y malos tratos a los que son sometidos los migrantes en el contexto de las devoluciones en caliente por parte de las fuerzas de seguridad de Marruecos. Son destacables, entre otros, el informe de Human Rights Watch de febrero de 2014, titulado "Abused and Expelled. Ill-Treatment of Sub-Saharan African Migrants in Morocco” (p. 8); el informe “International Activity Report 2012” de Médicos Sin Fronteras (2012, p. 66); las “Observaciones finales del Comité contra la Tortura, Marruecos, doc. ONU CAT/C/MAR/CO/4, de 2011" (Comité contra la Tortura, 2011, p. 4); y el Informe al Gobierno español sobre la visita a España del Comité Europeo para la Prevención de la Tortura del 14 al 18 de julio de 2014 (Consejo de Europa, 2014, párr. 54).

Así, se desprende claramente de estos informes que, los rechazos en frontera, en la medida en que los migrantes son puestos a disposición de las autoridades marroquíes, entrañan un riesgo auténtico de agresión, maltrato e incluso tortura. De esta forma, las autoridades españolas,

23 Sentencia del TEDH (Sección tercera) sobre el asunto Hilal c. Reino Unido, de 6 de marzo de 2001 (demanda n. $45276 / 99)$.

24 Sentencia del TEDH (Sala) sobre el asunto Abmed c. Austria, de 17 de diciembre de 2001 (demanda n. 25964/94).

25 Esta idea ha sido también establecida en, mutatis mutandis, los casos T. I. contra Reino Unido [Decisión de admisibilidad TEDH (Sección tercera), de 7 de marzo de 2000 (demanda n.o 43844/98)] (párrs. 456-457) y M. S. S. contra Bélgica y Grecia [sentencia del TEDH (Gran Sala) de 21 de enero de 2011 (demanda n.o 30696/09)] (párr. 342 ), siendo el primero de estos el caso donde por primera vez el TEDH trató el deber consistente en analizar este riesgo, que le corresponde al Estado, llegando incluso a considerar que las obligaciones derivadas de la Convención de Dublín no podían eliminar dicha responsabilidad (Morgades, 2012, p. 193).

26 Sentencia del TEDH (Pleno) sobre el asunto Soering c. Reino Unido, de 7 de julio de 1989 (demanda n.o $14038 / 88)$. 
sin poder razonablemente ignorar el potencial riesgo de tortura que corren los extranjeros expulsados en la frontera, estarían claramente infringiendo la prohibición contenida en el art. 3 $\mathrm{CEDH}^{27}$.

\subsection{Derecho a un recurso efectivo}

Este derecho está recogido en el art. $13 \mathrm{CEDH}$, en virtud del cual, "Toda persona cuyos derechos y libertades reconocidos en el presente Convenio hayan sido violados tiene derecho a la concesión de un recurso efectivo ante una instancia nacional, incluso cuando la violación ha sido cometida por personas que actúen en el ejercicio de sus funciones oficiales”. Así, la obligación de los Estados derivada de este artículo es la de garantizar la disponibilidad dentro del ordenamiento jurídico interno de una vía de recurso en caso de vulneración de un derecho garantizado por el CEDH. Tal y como ha establecido el TEDH en el caso Hirsi Jamaa (párr. 197) y en el caso Abdolkhani y Karimnia c. Turquiá ${ }^{28}$ (párrs. 107 y 115), este recurso debe garantizarse de forma efectiva tanto desde el punto de vista jurídico como desde el punto de vista práctico, sin que sea necesario que la mencionada efectividad dependa del grado de certeza sobre la resolución a favor o en contra del demandante. Además, el Tribunal establece también en el asunto Hirsi Jamaa que no resulta obligatorio que la autoridad ante la que se vaya a presentar el recurso sea una autoridad judicial, aunque en caso de no serlo, se examinarán los poderes y garantías ofrecidos por dicha autoridad como parámetros en orden a determinar si se trata de un verdadero recurso (párr. 197).

La jurisprudencia del TEDH ha establecido también que, en caso de que un demandante fuera a ser expulsado a un tercer Estado y presentara una queja respecto al riesgo que ello implicaría de sufrir tratos contrarios al art. $3 \mathrm{CEDH}$, dicha queja debería en tal caso ser examinada por una autoridad nacional de forma detenida, lo cual ha sido confirmado por el fallo del caso Shamayec y otros c. Georgia y Rusia ${ }^{29}$ (párr. 448). De acuerdo con este principio, el TEDH exige, con base en la interpretación de la noción de "recurso efectivo" recogido en el art. 13 en relación con el art. $3 \mathrm{CEDH}$, que la queja presentada por un demandante debe ser sometida a un examen riguroso e independiente, cuando existan razones para creer que dicho individuo corre riesgo de sufrir tratos prohibidos por el art. 3 según ha establecido el TEDH en el asunto Hirsi Jamaa (párr. 198), debiendo asimismo garantizarse que la ejecución de la medida im-

27 Resulta destacable el caso D. D.c. España, resuelto por el Comité de los Derechos del Niño de Naciones Unidas, en donde el Estado espańol ha sido condenado por un rechazo en frontera involucrando a un menor. En este caso, el Comité dictaminó que se había producido una violación de la prohibición de tortura consagrada en el art. 37 de la Convención de los Derechos del Nińo [Instrumento de Ratificación de la Convención sobre los Derechos del Niño, adoptada por la Asamblea General de las Naciones Unidas el 20 de diciembre de 1989 (BOE n.. 313, de 31 de diciembre de 1990)], habida cuenta, entre otros factores, de la violencia que sufren los migrantes en la zona fronteriza y de la ausencia de análisis por parte de las autoridades españolas del riesgo que suponía devolver al menor a Marruecos (Comité de los Derechos del Niño, 2019, p. 12).

28 Sentencia del TEDH (Sección segunda), sobre el asunto Abdolkhani y Karimnia c. Turquia, de 22 de septiembre de 2009 (demanda n.o 30471/08).

29 Sentencia del TEDH (antigua Sección segunda), sobre el asunto Shamayec y otros c. Georgia y Rusia, de 12 de abril de 2005 (demanda n.o 36378/02). 
pugnada es automáticamente suspendida, tal y como estableció el TEDH en el asunto $M$. $A$. yotros c. Lituania ${ }^{30}$ (párrs. 83-84).

Así, parece evidente la inconsistencia de las devoluciones sumarias con las obligaciones derivadas del art. $13 \mathrm{CEDH}$, en la medida en que resulta virtualmente imposible acceder a una vía de recurso efectiva en tanto en cuanto el individuo, al ser interceptado en la frontera, es rechazado automáticamente, sin posibilidad material de realizar alegación alguna ante las autoridades de una instancia doméstica, ni por tanto, de que se suspenda la expulsión. Por ello, podemos afirmar, sin que haya mucho lugar a dudas, que las expulsiones sumarias amparadas por la legislación española atentan directamente contra el art. $13 \mathrm{CEDH}$.

\subsection{Prohibición de expulsiones colectivas}

Este principio está garantizado en el art. 4 del Protocolo n.o 4 del CEDH, el cual reza de la siguiente forma: "Quedan prohibidas las expulsiones colectivas de extranjeros".

Se antoja necesario, con el objeto de comprender el alcance y la trascendencia de esta prohibición contemplada en el Convenio, examinar la jurisprudencia del Tribunal de Estrasburgo. El TEDH, en su fallo del caso Čonka contra Bélgica ${ }^{31}$, define la expulsión colectiva como cualquier medida por la que se obligue a un grupo de extranjeros a abandonar un Estado, con la excepción de que se tomen medidas por las que se proceda a examinar de forma objetiva y razonable el caso singular de cada extranjero que integre dicho grupo (párr. 59). Además, señala el TEDH en el asunto Hirsi Jamaa que esta prohibición busca "impedir que los Estados puedan expulsar a determinados extranjeros sin antes examinar sus circunstancias personales $\mathrm{y}$, de esta manera, sin dejarles presentar sus argumentos en contra de la medida adoptada por la autoridad competente" (párr. 177).

Así, conviene apuntar que el hecho de que varios extranjeros sean sometidos a decisiones parecidas no constituye en sí mismo una expulsión colectiva, siempre que cada uno de esos extranjeros haya tenido la posibilidad de argumentar a título individual contra su devolución ante las autoridades correspondientes, según estableció el TEDH en los asuntos Sultani c. Francia ${ }^{32}$ (párr. 81) y Hirsi Jamaa (párr. 177).

Asimismo, conviene señalar que, lo más significativo en orden a determinar si nos encontramos ante una expulsión colectiva, no es el criterio cuantitativo en base al cual examinaríamos si la medida ha recaído en un grupo de un mayor o menor número de personas, sino el criterio cualitativo en base al cual se debería analizar si dichas personas han tenido la posibilidad de realizar las oportunas alegaciones o si se ha dejado constancia de los individuos en cuestión o de las posibles necesidades de una especial protección (Martínez Escamilla y Sánchez Tomás, 2015, p. 27).

\footnotetext{
30 Sentencia del TEDH (Sección cuarta) sobre el asunto $M$. A. y otros c. Lituania, de 11 de diciembre de 2018 (demanda n.o 59793/17).

31 Sentencia del TEDH (Sección tercera) sobre el asunto Čonka c. Bélgica, de 5 de febrero de 2002 (demanda ก.․ 51564/99).

32 Sentencia del TEDH (Sección tercera) sobre el asunto Sultanic. Francia, de 20 de septiembre de 2007 (demanda ก.․ 45223/05).
} 
Por lo que respecta al concepto de "expulsión” al que se refiere esta prohibición, dicho concepto debe ser interpretado "en su sentido genérico, en el lenguaje corriente (ahuyentar de un lugar)”, tal y como estableció el TEDH en los asuntos Hirsi Jamaa (párr. 174) y Khlaifia y otros c. Italia 33 (en adelante, “Khlaifia y otros”) (párr. 243).

Se ha argumentado que el TEDH viene realizando una interpretación in crescendo de las garantías y derechos consagrados en el $\mathrm{CEDH}$, dotando a estos de una mayor efectividad y funcionalidad (Riemer, 2019). No obstante, en lo referente a la prohibición de expulsiones colectivas, el asunto Khlaifia y otros supuso un punto de inflexión a partir del cual el TEDH adoptó una deriva contraria a la interpretación "incremental” que venía siguiendo. En dicho asunto, estableció el Tribunal que "Article 4 of Protocol No. 4 does not guarantee the right of an individual interview in all circumstances; the requirement of this provision may be satisfied where each alien has a genuine and effective possibility of submitting arguments against his or her expulsion, and where those arguments are examined in an appropriate manner by the authorities of the respondent State” (párr. 248) ${ }^{34}$.

Sin embargo, las implicaciones derivadas de los rechazos en frontera en relación con el alcance y consecuencias de la prohibición de expulsiones colectivas parecen claras. Tal y como hemos visto, los rechazos en frontera, en la medida en que se basan en la interceptación de los extranjeros y la puesta a disposición automática de los mismos en favor de las fuerzas de seguridad marroquíes, no permiten de forma alguna ningún tipo de examen particular del caso del individuo en cuestión, sin que tampoco tenga este la posibilidad de presentar sus argumentos ante la decisión de la Administración de expulsarlo. De acuerdo con esta lógica, las devoluciones en caliente suponen una indiscutible violación de la prohibición contenida en el art. 4 del Protocolo n.o 4 del CEDH.

En este punto, cabe recordar la justificación del Ejecutivo español basada en la utilización del concepto de "frontera operativa", en virtud del cual los rechazos en frontera se producirían fuera de territorio español. Aunque haya quedado clara la inadmisibilidad jurídica de la que adolece dicho concepto, cabría de todas formas, aunque lo consideráramos válido, argumentar contra las devoluciones en caliente. De acuerdo con la jurisprudencia del TEDH, "cuando un Estado, mediante agente que opera fuera de su territorio, ejerce control y autoridad y, por lo tanto, su jurisdicción, sobre un individuo, tal Estado tiene obligación, en virtud del artículo 1, de garantizar a este individuo los derechos y libertades previstos en el Título I del Convenio que sean pertinentes en la situación de ese individuo”, según estableció el TEDH en el asunto Hirsi Jamaa (párr. 74). Tal y como asentó el TEDH en el mismo fallo, en la medida en que exista un control efectivo sobre los individuos implicados por parte de las autoridades, podremos en tal caso hablar de un ejercicio de iure atribuible al Estado en lo relativo a la jurisdicción, quedando sometidos a esta los individuos en cuestión (párr. 77).

Advierte el Tribunal también en el asunto Hirsi Jamaa que "si el artículo 4 del Protocolo Núm. 4 fuera aplicable solamente a expulsiones colectivas del territorio nacional de los Esta-

33 Sentencia del TEDH (Gran Sala) sobre el asunto Khlaifia y otros c. Italia, de 15 de diciembre de 2016 (demanda ก. $16483 / 12)$.

34 En esta línea de corte restrictivo, el TEDH admitió también en el asunto Khlaifia y otros, en lo concerniente al art. 13 comentado ut supra, que una medida de deportación no resulta contraria a dicho artículo cuando los demandantes no hayan alegado un riesgo de conculcación de los derechos derivados del art. 3 CEDH (párr. 281). 
dos parte al Convenio, una parte importante de las tendencias migratorias contemporáneas quedarían fuera de su ámbito de aplicación, a pesar de que el tipo de comportamiento que esta disposición busca evitar puede tener lugar fuera del territorio nacional” (párr. 177). Si bien en este último caso el Tribunal hacía referencia a expulsiones de migrantes por vía marítima, el razonamiento resultaría igual de aplicable ante las alegaciones del Gobierno sobre el concepto “operativo" de frontera. De esta forma, el Gobierno español no puede justificar los rechazos en frontera con base - que, como hemos comprobado, resulta insostenible - en que tienen lugar fuera de territorio español, pues incluso fuera de este rige lo dispuesto en el CEDH, en el caso de que las autoridades del Estado ejerzan un control efectivo sobre los individuos en cuestión. Así, en los rechazos en frontera, dicho control se manifestaría a través de la interceptación y la entrega de los extranjeros por parte de las fuerzas de seguridad del Estado. Por consiguiente, incluso en el hipotético caso de que se diera por válida la afirmación en base a la cual el triple vallado no se encuentra dentro del territorio español, la aplicación extraterritorial del CEDH, con el cumplimiento del correspondiente criterio del "control efectivo", nos permitiría afirmar que las devoluciones en caliente son contrarias al art. 4 del Protocolo n. 4 del CEDH.

\subsection{Principio de non-refoulement}

También conocido como principio de no devolución, constituye este uno de los pilares fundamentales en materia de derechos humanos, y concretamente en el derecho de asilo, hasta el punto de que existen autores que abogan por el reconocimiento de este principio como norma de ius cogens ${ }^{35}$ (Allain, 2001, p. 533). De acuerdo con la doctrina, dicho principio "impide devolver a un individuo a un territorio en el que su vida o integridad física y moral corran peligro” (I. González García, 2017, p. 42) ${ }^{36}$.

Pese a la ausencia de formulación expresa en el CEDH, el TEDH estableció ya en el año 1989, en el asunto Soering, que este principio estaba recogido de manera implícita en el art. $3 \mathrm{CEDH}$, anteriormente comentado (Kristín y Mjöll, 2019, p. 150), reconociendo su importancia posteriormente en varias ocasiones (M. S. S. contra Bélgica y Grecia (en adelante, “M. S. S."), párr. 286; M.A. c. Chipre $^{37}$, párr. 133). Por lo que respecta a la expulsión de solicitantes de asilo, el TEDH focaliza su preocupación en la debida existencia de "garantías efectivas que protejan al demandante contra una devolución arbitraria, directa o indirecta, hacia el país del que ha huido" (M.S.S., párr. 286).

El principio de no devolución lleva consigo la obligación de las autoridades de examinar, de forma previa a la devolución, la existencia de un riesgo real de sufrir tratos contrarios al art. 3

35 Pese a que la Comisión de Derecho Internacional de las Naciones Unidas no ha reconocido por ahora la naturaleza ius cogens de este principio, numerosos autores consideran que debería tener tal reconocimiento, considerándolo como una norma consuetudinaria de derecho internacional (Costello y Foster, 2016, p. 323).

36 Dicho principio se presenta en dos vertientes: por un lado, el refoulement directo, por el cual un individuo es expulsado a un país donde puede ser perseguido o sufrir tratos inhumanos, y por otro, el refoulement indirecto o en cadena, donde el individuo es expulsado a un Estado que a su vez puede proceder a expulsarlo a otro donde sufra persecución o tratos inhumanos (Gortázar Rotaeche, 2020, p. 44).

37 Sentencia del TEDH (Sección cuarta) sobre el asunto M. A. c. Chipre, de 23 de julio de 2013 (demanda ก. $41872 / 10)$. 
CEDH, considerando tanto la situación y condiciones del país de destino, como las circunstancias personales del individuo en cuestión, tal y como se estableció en los asuntos $F$. G. c. Suecia $^{38}$ (párr. 113) yJ. K. y otros c. Suecia ${ }^{39}$ (párrs. 86-87).

Por otro lado, la determinación del riesgo y la decisión de no devolución precisa de un nivel mínimo de severidad de los potenciales tratos prohibidos por el art. 3, a pesar de que dicho examen es relativo, y está supeditado a las circunstancias concretas de cada $\operatorname{caso}^{40}(F$. G. c. Suecia, párr. 112).

Asimismo, el TEDH estableció en el caso Hirsi Jamaa (párrs. 125-133), en relación con el alcance de las obligaciones estatales a la luz del art. $3 \mathrm{CEDH}$ analizadas anteriormente, que estas no están en ningún caso supeditadas a que la persona en cuestión sea -o afirme ser - un refugiado. En el caso mencionado, el TEDH estableció que la expulsión de cualquier persona, independientemente de su status como refugiado o no, al territorio de otro Estado, no puede en ningún caso acarrear el sometimiento a tratos prohibidos por el art. $3 \mathrm{CEDH}$. Por tanto, se deduce que la protección derivada del principio de non-refoulement, al amparo del art. $3 \mathrm{CEDH}$, abarca a cualquier migrante que pueda ser devuelto al territorio de un Estado potencialmente inseguro.

En relación con los indicios sobre el riesgo que pueda suponer la expulsión del migrante a otro Estado, el TEDH anteriormente ha tomado en consideración los informes provistos por organizaciones de protección de los derechos humanos, incluido el Comité Contra la Tortura de Naciones Unidas, tal y como se comprobó en el caso Daoudic. Francia ${ }^{41}$ (párr. 68).

Así, existen sobrados indicios, comentados ut supra, sobre el riesgo auténtico de padecer los actos recogidos en el art. $3 \mathrm{CEDH}$ como consecuencia de la expulsión de los inmigrantes a territorio marroquí. A mayor abundamiento, la inmediatez y automaticidad de esta práctica la hace incompatible con cualquier tipo de evaluación sobre un riesgo de sufrir tratos que atenten contra el art. 3. Por lo que respecta al grado de severidad de los tratos recibidos, un estudio realizado por la Agencia Estatal Consejo Superior de Investigaciones Científicas y ACNUR ha constatado que gran parte de los abusos que se producen en las zonas fronterizas incluyen violencia e incluso tiroteos (ACNUR, 2019, p. 28).

38 Sentencia del TEDH (Gran Sala) sobre el asunto F. G. c. Suecia, de 23 de marzo de 2016 (demanda ก. $43611 / 11)$.

39 Sentencia del TEDH (Gran Sala) sobre el asunto J. K. y otros c. Suecia, de 23 de agosto de 2016 (demanda n.․․ 59166/12).

40 En el marco de la tendencia restrictiva que inició el Tribunal de Estrasburgo en el asunto Khlaifia y otros en torno a la interpretación de las garantías y derechos de migrantes, resulta reseñable en este sentido la consideración que realizó de la presión a la que estaban sometidas las autoridades de Italia en un centro de internamiento de extranjeros, factor que determinó que el trato dispensado por dichas autoridades a los demandantes no alcanzase el grado de severidad que exige el art. 3. (párrs. 197-199). En este sentido, no parece razonable admitir que una posible situación de presión en que se encuentren las autoridades españolas en un contexto de entradas irregulares de migrantes pueda dar carta blanca a dichas autoridades para expulsar a migrantes que corran riesgo de sufrir tratos contrarios al art. $3 \mathrm{CEDH}$, existiendo otras medidas más proporcionadas y razonables para restablecer la situación de legalidad.

41 Sentencia del TEDH (Sección quinta) sobre el asunto Daoudi c. Francia, de 3 de diciembre de 2009 (demanda n.o 19576/08). 
Por todo lo expuesto, las devoluciones sumarias son contrarias al principio de non-refoulement.

\section{Giro jurisprudencial del TEDH: el caso N. D. y N. T. contra España}

Tal y como hemos comentado ut supra, este caso ha sido el primero donde el TEDH ha examinado el fenómeno de los rechazos en frontera que tiene lugar en la frontera de Melilla. Mientras que la Sección tercera del TEDH condenó a España por violación del art. 4 del Protocolo n.o 4 y del art. $13 \mathrm{CEDH}^{42}$ — cuya ratificación, de acuerdo con nuestra tesis, cabía esperar-, la Gran Sala ha rectificado dicho fallo, estableciendo que las devoluciones en caliente que se produjeron el 13 de agosto de 2014 no violaron la legalidad establecida en el CEDH.

En relación con la justificación planteada por el Gobierno español basada en el concepto de frontera "operativa”, la Sección tercera no entró en el debate sobre la ubicación de la valla fronteriza ${ }^{43}$, limitándose únicamente a sustentar su argumentación en la doctrina de la extraterritorialidad respecto a la aplicación del CEDH (párr. 54). No obstante, y debiendo destacar este aspecto positivo de su fallo, la Gran Sala concluye que "it is not disputed that the events in issue took place on Spanish territory" (párr. 104) ${ }^{44}$. Así, se confirma el hecho apodíctico de nuestra tesis, con base en el cual, el vallado fronterizo, en el cual acaecen los rechazos en frontera, está ubicado en territorio español.

\subsection{La conducta de los extranjeros como factor determinante}

El elemento decisivo que explica este giro copernicano en la decisión del TEDH es la consideración que surge en relación con la propia conducta de los demandantes, la cual estiman como un factor relevante en orden a determinar la protección recogida en el art. 4 del Protocolo n.o 4. Siguiendo esta línea, recuerda el TEDH la asentada jurisprudencia en base a la cual no

42 En lo referente a una posible conculcación del art. 3 CEDH, el TEDH rechazó en 2015 - en el trámite de admisión de la demanda de N. D. y N. T.— la reclamación realizada por violación de dicho precepto, al entender que la entrega a las autoridades marroquíes no conllevaba en ese supuesto un riesgo de sufrimiento de tortura o tratos inhumanos o degradantes, considerándose así a Marruecos como "país seguro" a los efectos de invocación del mencionado art. 3. Es por ello que Gortázar Rotaeche señala que —en lo atinente a las devoluciones en calienteaún no ha surgido el debate sobre el art. 3 y el concepto de país seguro (2020, p. 47), sino que el TEDH se deberá probablemente enfrentar a ello en un futuro (vid. nota 63). Así, la jurisprudencia en torno al principio de nonrefoulement no se ha visto modificada (Gortázar Rotaeche, 2020, p. 47). Al contrario, la Gran Sala insiste - a pesar de no ser trascendental para el caso- en el carácter absoluto de la prohibición contenida en el art. 3 (párr. 232). Sin embargo, surge la duda - con razón - sobre cómo van los Estados a involucrarse en rechazos en frontera y paralelamente atender sus obligaciones al amparo del art. 3 CEDH (Lübbe, 2020).

43 A este respecto, la Sección tercera señaló que "el TEDH se remite al derecho internacional aplicable y a los acuerdos celebrados entre los Reinos de Marruecos y de España que conciernen al establecimiento de las fronteras entre estos dos Estados. Considera sin embargo que no es necesario establecer si la valla fronteriza levantada entre Marruecos y España se sitúa o no en territorio de este último Estado” (párr. 54).

44 Es esta condición de territorio español la que la Gran Sala toma como fundamentación para asumir su jurisdicción, pues en lo atinente a la ficción de extraterritorialidad invocada en primera instancia, no hay rastro alguno en la sentencia que en estas líneas nos ocupa. 
cabe hablar de conculcación del art. 4 del Protocolo n. -4 en caso de que la propia conducta del demandante sea la causa de la ausencia de expulsión individual, donde encontramos los asuntos Hirsi Jamaa, Khlaifia y otros, M. A. c. Chipre, Dzavit Berisha y Baljie Haljitic. la Antigua República Yugoslava de Macedonia 45 (en adelante, "Berisha y Haljiti”), Dritsas y otros c. Italia ${ }^{46}$ (en adelante, "Dritsas y otros”) (párr. 200). Señala el Tribunal que los demandantes deliberadamente trataron de acceder a territorio español cruzando los dispositivos fronterizos de Melilla a través de una localización no autorizada, formando parte de un grupo numeroso de personas y mediante el uso de la fuerza, colocándose los demandantes de esta forma en una situación de ilegalidad (párr. 231). A su vez, los demandantes prescindieron de los cauces legales existentes en el momento ${ }^{47}$, que les hubieran permitido acceder a territorio español de forma regular, respetando así lo pertinente en relación con el cruce de fronteras del área Schengen, en virtud de lo establecido en el Código de fronteras Schengen (párr. 242). Además, considera el TEDH que los demandantes carecían de razones convincentes, ligadas a hechos objetivos atribuibles a España, con las que poder justificar la inutilización de las vías legales previstas para entrar en territorio español (párr. 229).

No obstante, debemos destacar que los casos señalados por el TEDH —en relación con la conducta de los demandados como factor relevante- presentan hechos sustancialmente distintos a los que se dan en el caso $N$. D. y N. T. Mientras que, en los casos traídos a colación por el TEDH, o bien se llegó a iniciar un procedimiento individualizado donde efectivamente los demandantes pudieron ejercer sus derechos, como en los casos Khlaifia y otros ${ }^{48}, M$. A. c. Chipre ${ }^{49}$ y Berisha y Haljiti ${ }^{50}$, o bien las autoridades tomaron las medidas iniciales con el

45 Decisión de admisibilidad del TEDH (Sección quinta), sobre el asunto Dzavit Berisha y Baljie Haljiti c. la Antigua República Yugoslava de Macedonia, de 16 de junio de 2005 (demanda n.o 18670/03).

46 Decisión de admisibilidad del TEDH (Sección segunda) sobre el asunto Dritsas y otros c. Italia, de 1 de febrero de 2011 (demanda n.o 2344/02).

47 En ese sentido, el Tribunal examinó si España había puesto a disponibilidad de los demandantes "genuine and effective access to means of legal entry” en su territorio, que constituye el otro requisito a examinar, además de la conducta del interesado, con el objeto de determinar si un Estado demandado está dispensado de llevar a cabo un procedimiento individualizado de expulsión (párr. 201). Concluye el Tribunal que, entre los medios legales al alcance de los demandantes para entrar en España, estaban a su disposición el puesto fronterizo de Beni Enzar, además de consulados y embajadas españolas donde los demandantes pudieron haber solicitado protección internacional, de acuerdo con la legislación española (párr. 222).

48 En el caso Khlaifia y otros, el TEDH concluyó que no se produjo una violación del art. 4 del Protocolo n.o 4, en la medida en que los demandantes tuvieron una auténtica y efectiva posibilidad de presentar argumentos en contra de su expulsión, teniendo en cuenta que su nacionalidad fue determinada y que fueron identificados en dos ocasiones (párr. 254). No obstante, es evidente que dicha posibilidad no estuvo al alcance de los demandantes en el caso de España, puesto que los rechazos en frontera, en la medida en que se basan en la interceptación y entrega automática de extranjeros por la vía de hecho, no permiten ni la realización ni registro de alegaciones en contra de la expulsión.

49 En el caso M. A. c. Chipre, un grupo de sirios kurdos argumentó que las órdenes de deportación y las cartas a tal efecto estaban redactadas en términos idénticos. No obstante, el TEDH concluyó que el proceso que llevó a determinar la deportación se realizó de manera individualizada y en atención a los hechos particulares de cada persona, por lo que no se produjo una expulsión colectiva (párr. 254). En contraste, en el caso N. D. y N. T. 一tal y como ocurre en los rechazos en frontera- no hubo proceso alguno de individualización.

50 En el caso Berisha y Haljiti, los demandantes demandaron a la antigua República Yugoslava de Macedonia argumentando en contra de la decisión común que recibieron en relación con su solicitud de asilo, inadmitiendo el TEDH la demanda y concluyendo que los hechos denunciados no habían implicado una expulsión colectiva 
objeto de iniciar dicho proceso, como en el caso Dritsas y otros ${ }^{51}$, en el caso que nos ocupa, en contraste, no se llegó a iniciar dicho proceso de identificación, sino que directamente se procedió a la devolución de los individuos sin intento alguno de dotarles de unas mínimas garantías procedimentales. De esta forma, es evidente la abismal diferencia que existe, en lo relativo al contexto y hechos que motivan la denegación de procedimiento, entre los casos a los que se refiere el TEDH y el caso de $N$. D. y $N$. T.

Asimismo, consideramos que suscita una gran cuestionabilidad, desde el punto de vista jurídico, la aproximación que realiza el Tribunal en su razonamiento sobre el hecho de que los demandantes accedieran a territorio español de forma irregular. En opinión del Tribunal, como consecuencia de esta entrada ilegal y uso de la violencia, los demandantes "pierden" su derecho a un procedimiento de identificación y a la posibilidad de realizar alegaciones en relación con sus circunstancias personales, además de que se documente y quede constancia de dicha actuación. Sin embargo, en materia de extranjería, a los asaltos a la valla fronteriza que caracterizan los rechazos en frontera, les es de aplicación el art. 58.3 LOEx comentado anteriormente, en lo relativo a su régimen sancionador. En virtud del citado artículo, respecto a los extranjeros "que pretendan entrar ilegalmente en España" ${ }^{2}$, se procedería a la devolución de los mismos sin necesidad de apertura de expediente ${ }^{53}$. Esta devolución, considerada como medida tendente a restaurar el orden jurídico vulnerado, carece así de carácter sancionador, tal y como dictaminó el Tribunal Constitucional en la STC 17/2013, de 31 de enero (FJ 12). Por tanto, teniendo en cuenta que el intento de entrada ilegal en España de la que derivan los rechazos en frontera, cuya consecuencia no tiene naturaleza sancionadora, y a diferencia de la expulsión, no se califica como infracción grave de acuerdo con la legislación en materia de extranjería ${ }^{54}$, resulta claramente desproporcionado admitir, por parte del TEDH, que los mi-

puesto que la interposición de la solicitud de asilo la realizaron de forma conjunta, aportaron los mismos medios de prueba y presentaron la solicitud de apelación de manera conjunta (Unidad de prensa del TEDH, 2020, pp. 6-7). Las circunstancias de este caso difieren sobremanera de las relativas al caso $N . D . y N$. T. en la medida en que en este último los demandantes no tuvieron oportunidad de interponer solicitud de ningún tipo.

51 En el caso Dritsas y otros, el TEDH inadmitió la demanda en relación con una expulsión colectiva, puesto que los demandantes, al ser requeridos sus documentos de identificación, desobedecieron a las autoridades, por lo que estas últimas no tuvieron posibilidad material de redactar órdenes de expulsión donde constasen los nombres correspondientes de las personas (Unidad de prensa del TEDH, 2020, p. 7). Sorprende la invocación de este caso por parte del TEDH en la medida en que a los demandantes del caso $N$. D. y N. T. no se les requirió en ningún momento sus documentos de identificación.

52 Resultaría coherente, en relación con este precepto, argumentar, de la forma en la que lo hemos hecho en este artículo, que los extranjeros involucrados en los rechazos en frontera se encuentran ya en territorio español, una vez superada la valla más externa y situados dentro del triple vallado fronterizo, por lo que no sería de aplicación el mencionado artículo. No obstante, señala el art. 23.1.b) RLOEx, respecto a qué se entiende por extranjeros "que pretendan entrar ilegalmente en España", que se incluye dentro de estos, a "los extranjeros que sean interceptados en la frontera o en sus inmediaciones".

53 Conviene apuntar, en este sentido, que la ausencia de expediente no es equivalente a una ausencia de procedimiento, aunque este se caracterice por una mayor simplicidad. En líneas generales, el procedimiento de devolución regulado en el art. 23 RLOEx, garantiza la identificación de los individuos interceptados, además de un estudio particular de la situación de los mismos y que se registre que han tenido la posibilidad de solicitar asilo, además de asistencia jurídica y de intérprete, en su caso, tal y como hemos comentado ut supra. Asimismo, cumple este régimen con los requisitos exigidos por el TEDH a este respecto (González García, 2015, p. 323).

54 Dentro de las modalidades de expulsión —en el sentido lato de la palabra — que existen en España, es significativo dónde está ubicado cada procedimiento en el RLOEx: mientras que procedimiento de expulsión stricto sensu 
grantes involucrados en este tipo de actuaciones vean mermados sus derechos hasta el extremo de ser privados de las mínimas garantías procesales reconocidas en la legislación nacional y por la jurisprudencia del TEDH, inherentes tanto a los procedimientos de devolución como de expulsión. Así, podríamos calificar como desmesurado el hecho de que el TEDH admita este recorte de derechos ante la infracción de una norma de carácter meramente administrativo (que no penal).

\subsection{La controvertida accesibilidad de los cauces legales de entrada en España}

La principal objeción en relación con el fallo de la Gran Sala se basa, desde nuestro punto de vista, en la inadmisible postura que adopta el Tribunal respecto al contexto y particularidades que caracterizan la frontera hispano-marroquí. Si bien el TEDH se basa en la posibilidad de la que disponían los demandantes para utilizar los cauces legales dispuestos por el ordenamiento jurídico español con el objeto de entrar en España, dicha posibilidad es manifiestamente irreal. Aunque resulta innegable que existen oficinas de asilo donde solicitar protección internacional o visados, así como puestos fronterizos a través de los que acceder a territorio español de forma legal, resulta del todo reveladora la preocupación que ha mostrado el Comisario para los Derechos Humanos del Consejo de Europa en este sentido. Dicha preocupación se fundaría en el hecho de que, "in practice only asylum-seekers from Syria can access the asylum office through the Moroccan border". A mayor abundamiento, en relación con el puesto de control fronterizo ubicado en territorio marroquí, las fuerzas policiales de Marruecos deniegan el acceso a migrantes de ciertas nacionalidades, pero especialmente a aquellos de origen subsahariano $^{55}$ (Consejo de Europa, 2015, párr. 30). Ante el contexto expuesto, no hay lugar a dudas de que muchos migrantes que quieren acceder a territorio español no tienen otra opción sino penetrar de forma irregular en el país superando el vallado fronterizo. Con esto en mente, resulta muy chocante que el TEDH haya afirmado que los demandantes tenían a su disposición "genuine and effective access to Spanish territory" (párr. 201), suscitando una gran cuestionabilidad sobre la exigencia por parte del Tribunal de agotar las vías domésticas de acceso a España, cuando estas, en la práctica, no existen a los ojos de muchos migrantes, incluyendo los demandantes - de origen subsahariano- del caso N. D. y N.T.

Esta cuestión es tratada por el TEDH a raíz de los informes presentados al respecto por el mencionado Comisario para los Derechos Humanos del Consejo de Europa, así como por ACNUR. No obstante, considera el Tribunal que dichos informes "are not conclusive as to the reasons and factual circumstances underlying these allegations. Some of them mention racial profiling or severe passport checks on the Moroccan side. However, none of these re-

se encuentra recogido en el Título XIV, sobre "Infracciones en materia de extranjería y su régimen sancionador", el procedimiento de devolución, teóricamente aplicable a los casos de entradas ilegales en el contexto de rechazos en frontera, se incluye en el Título I, concerniente al "régimen de entrada y salida de territorio español" (González García, 2015, p. 35).

55 Organizaciones como Médicos sin Fronteras (Alami, 2012), la Comisión Española de Ayuda al Refugiado (2017, p. 24), Amnistía Internacional (2015, p. 40) e incluso el Defensor del Pueblo (2016, p. 54) han denunciado las estrategias de evaluación y fichaje racial adoptadas por agentes de la policía marroquí, con el objeto de restringir el acceso a Espańa desde territorio marroquí de migrantes subsaharianos, lo que explica que a la oficina de Beni Enzar solo puedan acceder en la práctica personas de nacionalidad siria, argelina y yemení (Saez, 2017). 
ports suggests that the Spanish Government was in any way responsible for this state of affairs” (párr. 218). Asimismo, advierte el Tribunal, en relación con la necesidad de que los derechos recogidos en el Convenio se garanticen de forma efectiva y práctica, que no implica "a general duty for a Contracting State under Article 4 Protocol No. 4 to bring persons who are under the jurisdiction of another State within its own jurisdiction". Siguiendo este hilo argumental, afirma el TEDH más adelante, en lo relativo a la accesibilidad al puesto fronterizo de Beni Enzar, que "even assuming that difficulties existed in physically approaching this border crossing point on the Moroccan side, no responsibility of the respondent Government for this situation has been established before by the Court” (párr. 221).

Desde nuestro punto de vista, las implicaciones de este razonamiento son desconcertantes. En primer lugar, aunque susceptible de ser puesto en cuestión en mayor o en menor medida, el TEDH parece pasar por alto, de forma intencionada, las evidencias existentes, registradas por ONG y organizaciones internacionales dedicadas a la protección de los derechos humanos, en relación con las posibilidades de acceso a las vías legales de entrada en España, como los puestos fronterizos y consulados. En segundo lugar y más importante, se deduce de forma clara de las afirmaciones del TEDH que los puestos fronterizos de un país, estando situados en territorio del otro, no son por ello responsabilidad del primero, en lo relativo a su accesibi$\operatorname{lidad}^{56}$. En el caso que nos ocupa, incluso asumiendo que existen dificultades para acceder al puesto fronterizo de Beni Enzar, en tanto en cuanto este está situado en territorio marroquí, España no puede ser declarada responsable en ese sentido. Pese a ello, a los demandantes se les exige utilizar vías como la citada, y en caso de no hacerlo, se le permite al Estado privarle de los derechos recogidos en el Convenio. De esta forma, podemos afirmar que el razonamiento del TEDH es cuanto menos paradójico: a los demandantes, en orden a disfrutar de los derechos garantizados por el Convenio, se les exige recurrir a unas vías legales de entrada en el territorio de un Estado. Sin embargo, a este último, en tanto que dichas vías se institucionalizan en unas oficinas situadas en territorio extranjero, no se le exige que garantice su accesibilidad y funcionalidad. Así, aunque materialmente no exista posibilidad de acceder a dichas vías, los demandantes - a ojos del TEDH - son susceptibles de recriminación y de sanción, en tanto en cuanto no han hecho uso de estas vías, en vista de lo cual el Estado tiene derecho a privarlos del procedimiento individualizado de expulsión que reconoce el $\mathrm{CEDH}^{57}$.

Finalmente, conviene resaltar un tema que, por limitaciones de espacio, no abordaremos en profundidad en este artículo, que es la cuestión del acceso al procedimiento de asilo, teniendo en cuenta la ausencia del reglamento de aplicación de la Ley 12/2009, de 30 de octubre, reguladora del derecho de asilo y de la protección subsidiaria ${ }^{58}$ (en adelante, "Ley de Asilo") ${ }^{59}$.

56 Conviene destacar que, en materia de asilo, ni la legislación interna, ni la Convención de Ginebra, ni la legislación comunitaria regulan de forma alguna las restricciones y limitaciones de accesibilidad en lo concerniente a las solicitudes de asilo o de protección internacional que estén supeditadas a los cauces de acceso al territorio de España (Arce Jiménez, 2017, p. 59).

57 Sin perjuicio de la evidente problemática que suscitaría exigir a España la garantía de accesibilidad a sus instancias situadas en Marruecos, hubiera resultado lógico que, eximiendo a España de garantizar dicha accesibilidad, los demandantes no hubieran sido recriminados por no haber hecho uso de dichas instancias al no ser estas accesibles. Así, resulta del todo relevador que el Tribunal no se moleste en hacer esta precisión, pero que sí apunte que España no podría ser declarada como responsable en cualquier caso en lo relativo a la accesibilidad a sus instancias en el extranjero. 
Esta cuestión es tratada por la Gran Sala en tanto en cuanto los demandantes y el Gobierno discuten la eficacia protectora del art. 38 de la Ley de Asilo, relativo a las "solicitudes de protección internacional en Embajadas y Consulados”. En este sentido, argumentan los demandantes que el mencionado artículo carecía aún del desarrollo reglamentario necesario y que, por tanto, no resultaba de aplicación. Sin embargo, el TEDH estimó que esta afirmación era errónea en la medida en que el Ejecutivo español había demostrado esto "pointing out that according to Article $2 \S 2$ of the Civil Code, laying down implementing arrangements for the previous version of the Law on asylum, was still in force" ${ }^{30}$ (párr. 224). A pesar de que, como hemos señalado, no vamos a entrar en el interesante análisis sobre si el nivel de protección dispensado por el reglamento anterior, aprobado mediante el Real Decreto 203/1995, de 10 de febrero $^{61}$, y aún vigente, resultó ser suficiente en el caso que nos ocupa, sí nos gustaría poner de manifiesto la contradicción en la que parecen incurrir nuestros Gobiernos en este sentido. Por un lado, el Gobierno presidido por el Partido Popular en el 2016, fue preguntado acerca del consulado de Nador y de la posibilidad de solicitar protección internacional para los migrantes subsaharianos, a lo que contestó que resultaba necesaria la aprobación del nuevo reglamento (Sánchez Tomás, 2018). Contrasta con ello el argumento del Estado en este caso, presidido por el Gobierno Socialista, sobre la suficiencia del reglamento anterior en la regulación de esta cuestión. Así, en la medida en que carece de lógica que el color del Ejecutivo explique esta contradicción, podemos afirmar que el Estado, en defensa de sus propios intereses, ha optado por negar la necesidad de una nueva regulación, con el objetivo de resultar eximido de una responsabilidad que a todas luces le es atribuible.

Del fallo de este caso, habida cuenta del giro de ciento ochenta grados que experimenta en relación con la decisión de primera instancia, se han hecho eco un gran número de medios de comunicación. Varios de los principales diarios a nivel nacional —incluidos El Pais, La Vanguardia ${ }^{62}$ y El Mundo - han tratado el caso, afirmando, respecto al fallo del TEDH, que este último ha "avalado" las devoluciones en caliente (Ayuso, 2020; Val, 2020; Marraco y Álvarez, 2020). Consideramos estas afirmaciones como un punto de partida ideal para matizar y analizar, desde el rigor y el espíritu crítico, las implicaciones del fallo respecto a lo que se denomina de forma general "devoluciones en caliente".

Desde nuestro punto de vista, el fallo de la Gran Sala lo que ha hecho es avalar las devoluciones en caliente que se produjeron el 13 de agosto de 2014, unas expulsiones colectivas que, como he-

59 La aprobación de este reglamento está pendiente desde que la citada ley fue promulgada en el año 2009. Establece su art. 38 in fine: "El Reglamento de desarrollo de esta Ley determinará expresamente las condiciones de acceso a las Embajadas y Consulados de los solicitantes, así como el procedimiento para evaluar las necesidades de traslado a España de los mismos". Vid., respecto a las implicaciones de la falta de este reglamento, García Victoria, I. (2018). Una década sin reglamento de asilo en España. Obstáculos e interpretaciones divergentes. Anuario CIDOB de la Inmigración 2018, pp. 116-128.

60 Continúa diciendo el Tribunal que "That decree provided for a specific procedure enabling the ambassadors to establish whether asylum applications submitted at the Spanish embassies and consulates were genuine and, if appropriate, to arrange for the transfer to Spain of the persons concerned, by means of an urgent admission in the event of a high risk in the third country" (párr. 224).

61 BOE n.o 52, de 2 de marzo de 1995, pp. 7237-7246.

62 Se ha llegado a afirmar por parte de este medio que "el TEDH considera que las devoluciones sumarias son legales y no contrarias a los derechos humanos” (Val, 2020). 
mos comprobado, se caracterizaron por una entrada de forma irregular, en la que los demandantes se prevalieron del gran número de personas involucradas y donde utilizaron la fuerza.

No obstante, estos últimos hechos no son necesariamente característicos, de acuerdo con la definición de "devolución en caliente" proporcionada ut supra, de absolutamente todas las entradas ilegales previas a dichas expulsiones. Así, la potencial variedad de hipotéticos escenarios en este contexto nos permite afirmar que se pueden haber producido, y de seguro se producirán en un futuro, entradas ilegales de un número reducido de personas, donde las mismas no utilicen necesariamente la fuerza, y respecto de las cuales el TEDH podría reconocer como de forma insensata no ha hecho en esta ocasión - que en efecto no existen medios genuinos y efectivos de entrada en territorio español. En la medida en que estos últimos hechos han sido determinantes en la valoración y fallo del TEDH, no podemos afirmar que estando estos hechos ausentes y manteniéndose el resto igual, el Tribunal "avalaría” cualesquiera devoluciones en caliente $e^{63}$.

Así, no cabe afirmar — de la forma en la que lo ha hecho la prensa - que el TEDH haya reconocido la validez de lo que generalmente se entiende por "devoluciones en caliente". Como decimos, sin ánimo de restarle importancia y reconociendo la preocupación que suscita, el TEDH ha admitido unas expulsiones con unas determinadas características ${ }^{64}$, acaecidas en un contexto en particular. Sin embargo, sí conviene señalar que el caso de $N$. D. y N. T. constituía una oportunidad ideal para el TEDH de establecer una interpretación más garantista respecto a la prohibición de expulsión colectiva recogida en el Protocolo n.o 4 del CEDH. En cambio, el Tribunal de Estrasburgo, ante una clara disyuntiva entre exigir responsabilidad a las personas o al Estado, ha optado claramente por eximir a este último, llegando al extremo inconcebible de atribuir a las personas una obligación que resulta ser, en atención a las circunstancias, manifiestamente inexigible. De esta forma, el Tribunal ha adoptado una interpretación del CEDH claramente restrictiva de los derechos humanos, sentando con ello un precedente sumamente peligroso en lo relativo a la protección dispensada por la prohibición de expulsiones colectivas recogida en el CEDH.

\section{La externalización fronteriza y los rechazos en frontera}

Tras la reflexión precedente, cabría sostener que el fin de las devoluciones en caliente sería posible si el Estado español tuviera la voluntad de poner en práctica políticas migratorias que

63 Conviene señalar que los casos Doumbe Nnachui c. España (demanda n.o 19420/15) y Balde y Abel c. España (20351/17), actualmente pendientes de admisibilidad en el TEDH, suponen para este último una oportunidad de corregir lo establecido en el caso $N$. D. y N. T. respecto a los rechazos en frontera. Además, resulta destacable, por un lado, que ambas demandas alegan la conculcación del art. $3 \mathrm{CEDH}$ y, por otro lado, que el caso Balde y Abel c. España se refiere a hechos acaecidos una vez entrada en vigor la reforma legislativa llevada a cabo mediante la DAD, por lo que el TEDH tendría ocasión de pronunciarse sobre este extremo.

64 En este sentido, se ha señalado que el TEDH podría todavía modular la aprobación otorgada a los rechazos en frontera, teniendo en cuenta la inadmisión de la argumentación relativa a la jurisdicción y del concepto de expulsión esgrimido en el procedimiento por los Estados intervinientes (Sánchez Legido, 2020, p. 257), en virtud del cual los Gobiernos de Italia, Francia y Bélgica, en apoyo del Estado español, argumentaron que los rechazos en frontera no podían entenderse como expulsiones bajo el alcance del art. 4 del Protocolo n. 4 del CEDH (Sánchez Legido, 2020, p. 248). 
respetaran las garantías jurídicas que le corresponde a todo migrante al amparo de la normativa de derechos humanos.

No obstante, desde nuestro punto de vista, se podría incluso ir más allá del ámbito de lo que estrictamente abarcan los procesos de expulsión de migrantes que, como hemos examinado, están regulados de forma minuciosa en nuestra legislación nacional. Con el caso N. D. y N. $T$., hemos palpado la controversia que suscita actualmente la cuestión de la accesibilidad a las vías legales implantadas en el extranjero con el objeto de permitir a migrantes acceder de forma regular a nuestro territorio nacional o de que soliciten asilo o protección internacional. Así, parece lógico que garantizando el Estado dicha accesibilidad, se reducirían por tanto los intentos de acceso irregular a nuestro país, ergo disminuiría la posibilidad de que se llevaran a cabo rechazos en frontera.

De esta forma, surge la cuestión de cómo garantizar que los migrantes tengan un acceso real y efectivo a los cauces legalmente establecidos que les permitan entrar en España y solicitar la protección que corresponda. La respuesta a esta cuestión nos lleva de nuevo al propio Estado y su adopción de una estrategia en boga incluso en la Unión Europea ${ }^{65}$ : la externalización del control fronterizo ${ }^{66}$.

Pese a que por razones de espacio no vamos a analizar esta cuestión con toda la prolijidad que nos gustaría, sí consideramos conveniente introducir este tema y examinar en la medida de lo posible las extraordinarias implicaciones que acarrea en relación con las devoluciones en caliente.

La externalización del control fronterizo es definida por la doctrina como "todas las prácticas llevadas a cabo por los Estados con el objetivo de trasladar la frontera, desplazándola de una simple frontera física hacia cualquier lugar donde se puedan encontrar los migrantes" (Poncela, 2018, p. 5). En el caso del Estado español, una de las múltiples modalidades de externalización de fronteras se traduce en diversos acuerdos ${ }^{67}$, en el marco también de la Unión Europea, en virtud de los cuales Marruecos ha incrementado el despliegue de cuerpos de policía y del ejército ante las vallas de Ceuta y Melilla, encargándose entre otras cosas, del desmantelamiento de campamentos establecidos por migrantes en las inmediaciones del territorio español (Garcés-Mascareñas, 2016) ${ }^{68}$. Así, se enmarcaría como estrategia de externalización de fronteras el papel adoptado por las autoridades marroquíes, denunciado por el comisario de Derechos Humanos para el Consejo de Europa, con el objeto de prevenir el acceso de muchos

65 El acuerdo entre la UE y Turquía del 18 marzo de 2016, citado al inicio de este artículo, ha sido calificado por la doctrina como estrategia de externalización fronteriza, en tanto en cuanto dicho acuerdo implicaba esencialmente delegar en las autoridades turcas el control de la frontera comunitaria hacia el sureste entre Grecia y Turquía (Üstübici y İçduygu, 2018, p. 26).

66 A mayor abundamiento, estas estrategias son adoptadas en un contexto de endurecimiento de políticas migratorias por parte de los Estados del continente europeo (Goig Martínez, 2017, p. 97).

67 Sin perjuicio de la significación de los acuerdos de España con Marruecos en tanto que país limítrofe, el Estado español también ha firmado acuerdos con otros países de los que proviene un gran porcentaje de la inmigración venida de la África subsahariana, tales como Gana, Senegal, Mali, Costa de Marfil, Guinea y Gambia (Garcés-Mascareñas, 2016).

68 Afirma Frontex, en el mismo sentido, que "the dismantling of makeshift migrant camps in Morocco and Algeria might act as a 'push factor' in displacing migrants to other areas” (Gálvez, 2017). 
migrantes a los puestos de control fronterizo o a las oficinas de asilo, derivando esta actuación en la imposibilidad de acceso a estas vías ${ }^{69}$.

Así, se deduce la relación, cuanto menos peculiar, que se da entre esta modalidad de externalización de fronteras y las devoluciones en caliente. España, presumiblemente con el objetivo de reducir la entrada de inmigrantes en su país por vías regulares, recurre a la cooperación de Marruecos ${ }^{70}$ para reducir el número de solicitantes en sus instancias situadas en dicho país. Consecuentemente, los migrantes que ven obstaculizado su acceso a dichas vías se ven entonces forzados a intentar entrar en España de forma irregular, con lo que las autoridades españolas recurren así a los rechazos en frontera.

De esta forma, cabría sostener en cierta medida que la externalización de fronteras adoptada por España constituye una suerte de causa mediata o indirecta de las devoluciones en caliente, en tanto en cuanto, las entradas irregulares características de este tipo de prácticas se producen como consecuencia de la inaccesibilidad a los cauces legales de entrada en Marruecos, inaccesibilidad de la que es responsable el propio Estado español debido al empleo de mecanismos de externalización fronteriza.

Consecuentemente, en la medida en que no cese la externalización fronteriza que hemos examinado, continuarán produciéndose entradas de forma irregular en España, ante las cuales, a la vista del fallo de la Gran Sala, responderá el Estado español — con la connivencia del TEDH - mediante devoluciones en caliente.

\section{Conclusiones}

1. En suma, podemos afirmar que los rechazos en frontera contravienen radicalmente la legalidad internacional y nacional. Por una parte, la expulsión de los extranjeros a territorio marroquí, en tanto en cuanto supone un verdadero riesgo de abusos y malos tratos por parte de las fuerzas de seguridad de Marruecos, contraviene de forma patente la prohibición de tortura y el principio de non-refoulement. Por otra parte, la ausencia de cualquier forma de procedimiento de individualización y audiencia al extranjero se traduce en un atentado frontal, a la luz de la jurisprudencia del TEDH, contra la prohibición de expulsiones colectivas y el derecho a un recurso efectivo ante una violación de un derecho consagrado en el CEDH.

69 En relación con la veracidad de estas afirmaciones, resulta del todo significativo un informe del Representante Especial del Secretario General del Consejo de Europa en materia de migración y refugiados, donde se afirma, al respecto de la prevención de acceso a territorio español desde Marruecos y la cooperación en materia de inmigración entre estos dos países, que "member states should exercise human rights due diligence in the context of such cooperation. They should take into account the situation in their neighbouring countries to refrain from sharing information with or requesting the latter to intercept people before they reach member states' borders when they know, or should have known, that the intercepted persons would as a result be exposed to a real risk of torture or inhuman degrading treatment or punishment and they would not be given protection in the neighbouring countries" (Consejo de Europa, 2018).

70 Respecto a los acuerdos concluidos por España en esta materia, una cuestión muy problemática es la de su opacidad, toda vez que en muchas ocasiones no hablamos de tratados internacionales, sino de acuerdos no normativos no vinculantes jurídicamente, de carácter confidencial, cuya vigencia y contenido resultan difíciles de determinar (González Vega, 2015, p. 183). 
2. Así, el fallo del caso $N$. D. y N. T. supone a priori una batalla perdida para el derecho internacional. El TEDH, considerado como último bastión europeo en la defensa de los derechos humanos, ha adoptado una postura a todas luces restrictiva de los derechos recogidos en el CEDH, pese a la jurisprudencia asentada en la materia, que con este fallo queda en gran medida desvirtuada. Cabría argumentar que, de ahora en adelante, la prohibición de expulsiones colectivas no será de aplicación a un gran número de migrantes y solicitantes de asilo o protección internacional que intenten traspasar la valla fronteriza de Ceuta o Melilla, en la medida en que el carácter irregular de sus entradas constituirá el pretexto necesario en orden a limitar los derechos que les corresponden al amparo del CEDH.

3. Además, el razonamiento del TEDH peca de contradictorio en la medida en que, atendiendo a las circunstancias, no termina de exigir a España que garantice la accesibilidad de los cauces legales habilitados en el extranjero para entrar en su territorio, pero requiere a migrantes y solicitantes de asilo utilizar dichos cauces, lo que en último término se traduce en una postura claramente punitivista. Así, el fallo del caso $N$. D. y N. T. añade un eslabón más en un proceso de endurecimiento de las políticas migratorias, al que se han sumado ya muchos Estados de Europa, contribuyendo así en un menoscabo de las garantías mínimas que le corresponden a migrantes y solicitantes de asilo.

4. Desde nuestro punto de vista, resulta clara la presión migratoria a la que se enfrenta el Estado español en tanto que frontera sur de Europa limítrofe con África. Sin embargo, esta presión no puede en ningún caso considerarse como justificación que exima a España de cumplir con sus obligaciones a la luz del derecho internacional. En relación con la regulación de la entrada, estancia y salida de extranjeros de un territorio nacional, los Estados soberanos, tal y como los concebimos hoy en día, ostentan a priori el derecho a ejercer el control que estimen oportuno. No obstante, dicho control debe respetar en todo caso lo dispuesto en el CEDH, tal y como ha establecido el TEDH en su jurisprudencia. Consecuentemente, el ejercicio de las competencias relativas a la gestión y control fronterizo está en todo caso supeditado al debido respeto y garantía de los derechos humanos que son inherentes a todas las personas envueltas en flujos migratorios.

5. De esta forma, futuras líneas de investigación deberían estudiar la potencialidad de una regulación del derecho de asilo que aborde la responsabilidad estatal en la garantía de accesibilidad y funcionalidad de los cauces legales de entrada en su territorio mediante los que se puede solicitar asilo o protección internacional y, especialmente, las implicaciones jurídicas que derivarían estando dichos cauces situados en el territorio de otro Estado.

6. Resulta evidente que la cuestión de la presión migratoria no debería ser abordada ni mediante estrategias de externalización fronteriza, ni mediante la creación de figuras como los rechazos en frontera, indirectamente promovidos por mor de las primeras. No podemos olvidar que el respeto de los derechos humanos constituye un límite insoslayable que debe en cualquier caso actuar de piedra angular en la regulación de todo lo concerniente con los procesos migratorios. No obstante, incluso cumpliendo con esto, puede resultar difícil la conciliación del interés por mantener la seguridad y frenar la inmigración irregular, y el debido respeto de los derechos humanos. Así, el fenómeno de la inmigración, tanto regular como irregular, precisa de una aproximación holística e integral, que incida de forma especial en las causas profundas que motivan a las personas a abandonar de forma forzosa sus países de origen. 


\section{Referencias}

ACNUR (2019). Refugees and Migrants arriving in Spain. Recuperado de: https:// www.refworld.org/docid/5c667adc7.html (última consulta 25/11/2020)

Acosta Sánchez, M. A. (2014). Las fronteras terrestres de España en Melilla: Delimitación, vallas fronterizas y "tierra de nadie". Revista Electrónica de Estudios Internacionales, 28. doi: $10.17103 /$ reei.28.07.

Alami, A. (2012). African Migrants in Morocco Tell of Abuse. The New York Times. Recuperado de: https://www.nytimes.com/2012/11/29/world/middleeast/african-migrants-inmorocco-tell-of-abuse.html (última consulta 04/04/2020)

Allain, J. (2001). The Jus Cogens Nature of Non-Refoulement. International Journal of Refugee Law, 13(4), 533-558. doi: 10.1093/ijrl/13.4.533.

Amnistía Internacional (2015). Fear and fences. Europe's approach to keeping refugees at bay. Recuperado de: https://www.amnesty.org/download/Documents/EUR0325442015ENGLISH.PDF (última consulta 04/04/2020)

Arce Jiménez, C. (2017). Dos años de devoluciones en caliente "legales". Derechos Humanos en la Frontera Sur (pp. 54-63). Sevilla: Asociación Pro Derechos Humanos de Andalucía. Recuperado de: https://apdha.org/media/informe-frontera-sur-2017-web.pdf (última consulta 03/04/2020)

Ayuso, S. (2020, Febrero 14). Estrasburgo avala las devoluciones en caliente de inmigrantes que saltan la valla en Ceuta y Melilla. El Pais. Recuperado de: https://elpais.com/politica/2020/02/13/actualidad/1581597061_111909.html (última consulta 29/02/2020)

Comisión Española de Ayuda al Refugiado (2017). Refugees and migrants in Spain: the invisible walls beyond the sourthern border. Recuperado de: https://www.cear.es/wpcontent/uploads/2018/03/REPORT-MUROS-FRONTERA-SUR.pdfúltima consulta 06/04/2020) (última consulta 06/04/2020)

Comité de los Derechos del Niño (2019). Dictamen aprobado por el Comité en relación con el Protocolo Facultativo de la Convención sobre los Derechos del Niño relativo a un procedimiento de comunicaciones respecto de la Comunicación Núm. 4/2016 (CRC/C/80/D/4/2016). Recuperado de: https://www.refworld.org/cgi-bin/texis/vtx/ rwmain/opendocpdf.pdf?reldoc=y\&docid=5c73f8f54 (última consulta 16/04/2020)

Comité contra la Tortura (2011). Observaciones finales del Comité contra la Tortura, Marruecos, doc. ONU CAT/C/MAR/CO/4. Recuperado de: https://www.acnur.org/fileadmin/Documentos/BDL/2012/8698.pdf (última consulta 25/03/2020)

Consejo de Europa (2014). Report to the Spanish Government on the visit to Spain carried out by the European Committee for the Prevention of Torture and Inbuman or Degrading Treatment or Punishment (CPT) from 14 to 18 July 2014. Recuperado de: https:// www.refworld.org/docid/553e4fbc4.html (última consulta 07/04/2020)

Consejo de Europa (2015). Third party intervention by the Council of Europe Commissioner for Human Rights under Article 36, paragraph 3, of the European Convention on Human Rights Applications No. 8675/15 and No. 8697/15 N. D. v. Spain and N. T. 
v. Spain. Recuperado de: https://rm.coe.int/third-party-intervention-by-the-council-ofeurope-commissioner-for-hum/16806dac25 (última consulta 16/11/2020)

Consejo de Europa (2018). Report of the fact-finding misión by Ambassador Tomás Boček, Special Representative of the Secretary General on migration and refugees, to Spain, 18-24 March 2018. SG/Inf(2018)25. Recuperado de: https://search.coe.int/cm/ Pages/result_details.aspx?ObjectId=09000016808d2c31 (última consulta 15/04/2020)

Costello, C., \& Foster, M. (2016). Non-refoulement as Custom and Jus Cogens? Putting the Prohibition to the Test. Netherlands Yearbook of International Law 2015. Ius Cogens: Quo Vadis? (pp. 273-327). La Haya, Países Bajos: Asser Press. doi: 10.1007/978-94-6265-114-2_10.

Defensor del Pueblo (2016). Estudio sobre el asilo en España. La protección internacional y los recursos del sistema de acogida. Recuperado de: https://www.defensordelpueblo.es/ wp-content/uploads/2016/07/Asilo_en_Espa\%C3\%B1a_2016.pdf (última consulta $22 / 11 / 2020)$

Espiniella Menéndez, Á. (2016). Crítica al régimen especial de rechazos en la frontera de Ceuta y Melilla. Revista Española de Derecho Internacional, 68(2), 321-358. doi: 10.17103/ redi.68.2.2016.2.03.

Fernández Díaz (2014, Mayo 6). No hay devoluciones en caliente, sino rechazos en frontera. $A B C$. Recuperado de: https://www.abc.es/espana/20140505/abci-fernandez-diaz-devolucion-inmigrantes-201405051320.html (última consulta 15/03/2020)

Gálvez, J. J. (2017, Agosto 8). People smugglers double price of sea journeys into Spanish territory. El Pais. Recuperado de: https://english.elpais.com/elpais/2017/08/08/inenglish/1502176554_468693.html (última consulta 02/04/2020)

Garcés-Mascareñas, B. (2016). Frontera sur: laboratorio de las políticas europeas. $C I D O B$ - Barcelona Centre for International Affairs. Recuperado de: https://www.cidob.org/publicaciones/serie_de_publicacion/opinion/migraciones/frontera_sur_laboratorio_de_las_politicas_europeas (última consulta 04/03/2020)

García Victoria, I. (2018). Una década sin reglamento de asilo en España. Obstáculo e interpretaciones divergentes. Anuario CIDOB de la Inmigración, 116-128. doi: 10.24241/ anuariocidobinmi.2018.116.

Goig Martínez, J. M. (2017). La política común de inmigración en la Unión Europea en el sesenta aniversario de los Tratados de Roma (o la historia de un fracaso). Revista de Derecho de la Unión Europea, 32, 71-111.

González García, I. (2017). Rechazo en las fronteras exteriores europeas con Marruecos: inmigración y derechos humanos en las vallas de Ceuta y Melilla, 2005-2017. Revista General de Derecho Europeo, 43, 17-57.

González García, J. V. (2015). Expulsiones “en caliente”, devoluciones y petición de asilo en Ceuta y Melilla. Revista de Administración Pública, 196, 309-329.

González Sacaluga, L. F. (2017). La Gestión de la Seguridad en la Valla de Ceuta (Trabajo de fin de grado). Universidad de Las Palmas de Gran Canaria. 
González Vega, J. A. (2015). El control de la inmigración irregular en España: compromisos y desarrollos. Revista CIDOB d'afers internacionals, 11, 173-193.

Gortázar Rotaeche, C. (2020). ¿La nueva línea del TEDH es restrictiva? Claves de Razón Práctica. Inmigración, 270, 42-50.

Human Rights Watch (2014). Abused and Expelled: Ill-Treatment of Sub-Saharan African Migrants in Morocco. Recuperado de: https://reliefweb.int/sites/reliefweb.int/files/resources/morocco0214_ForUpload.pdf (última consulta 15/03/2020)

Kristin, E., \& Mjöll, O. (2019). Non-Refoulement in Strasbourg: Making Sense of the Assessment of Individual Circumstances. Oslo Law Review, 5(3), 147-174. doi: 10.18261/ issn.2387-3299-2018-03-02.

Lübbe, A. (2020). The Elephant in the Room. Effective Guarantee of Non-Refoulement after ECtHR N. D. and N. T.? Verfassungsblog. Recuperado de: https://verfassungsblog.de/ the-elephant-in-the-room/ (última consulta 26/11/2020)

Marraco, M., \& Álvarez, R. J. (2020, Febrero 13). Estrasburgo avala las “devoluciones en caliente” en Ceuta y Melilla y revoca la condena inicial a España. El Mundo. Recuperado de: https://www.elmundo.es/espana/2020/02/13/5e455c1dfc6c83ee098b46bc.html (última consulta 29/02/2020)

Martínez Escamilla, M., \& Sánchez Tomás, J. M. (2015). Devoluciones ilegales en la frontera sur. Análisis jurídico de las denominadas "devoluciones en caliente". Proyecto $I+D+i$ "Iusmigrante" (DER 2011-26449).

Martínez Escamilla, M., Sánchez Tomás, J. M., Segovia Bernabé, J. L., Díez Ripolés, J. L., García España, E., Gimbernat Ordeig, E., \& Villaverde Menéndez, I. (2014). “Expulsiones en caliente": Cuando el Estado actúa al margen de la ley. Informe promovido desde el Proyecto I+D+i "Iusmigrante" (DER 2011-26449). Recuperado de: http://eprints.ucm.es/25993 (última consulta: 25/02/2020)

Martínez Escamilla, M., Sánchez Tomás, J. M., Segovia Bernabé, J. L., Díez Ripolés, J. L., García España, E., Gimbernat Ordeig, E., \& Villaverde Menéndez, I. (2015). Rechazos en frontera”: ¿Frontera sin derechos? Informe promovido desde el Proyecto $I+D+i$ "Iusmigrante” (DER 2011-26449). Recuperado de: https://eprints.ucm.es/29379/1/Informe\%20rechazo\%20en\%20frontera.pdf (última consulta: 25/02/2020)

Médicos sin Fronteras (2012). International Activity Report 2012. Recuperado de: https:// www.msf.org/sites/msf.org/files/msf_activity_report_2012_interactive_final.pdf (última consulta 05/04/2020)

Morgades Gil, S. (2012). TEDH -- Sentencia de 21.01.2011 (Gran Sala), M. S. S. c. Bélgica y Grecia, 30696/09 -- "Artículos 3 y 13 CEDH - Prohibición de tortura y penas o tratos inhumanos o degradantes -- Reglamento (CE) No. 343/2003 de determinación del Estado responsable del examen de una solicitud de asilo (Dublín II)" -- El funcionamiento efectivo de la política europea de asilo ante la garantía del derecho a no sufrir tratos inhumanos o degradantes del CEDH. Revista de Derecho Comunitario Europeo, 41(343/2003), 183-204.

Poncela Sacho, A. (2018). La externalización de las fronteras en el ámbito de la Unión Europea. Boletín del Instituto Español de Estudios Estratégicos bie3, 11, 231-245. 
Riemer, L. (2019). The ECtHR as a drowning 'Island of Hope'? Its impeding reversal of the interpretation of collective expulsion is a warning signal. Verfassungsblog. Recuperado de: https://verfassungsblog.de/the-ecthr-as-a-drowning-island-of-hope-its-impending-reversal-of-the-interpretation-of-collective-expulsion-is-a-warning-signal/ (última consulta 27/11/2020)

Ruiz Sutil, C. (2016). El rechazo en frontera o la denominada "devolución en caliente" y su regulación en la LOEx. Revista Española de Derecho Internacional, 68(2), 329-336. doi: 10.17103/redi.68.2.2016.2.04.

Saez, S. (2017, Noviembre 16). Melilla: No asylum for black men. Deutsche Welle. Recuperado de: https://www.dw.com/en/melilla-no-asylum-for-black-men/a-41404179(última consulta 05/04/2020)

Sánchez Legido, A. (2020). Las devoluciones en caliente españolas ante el Tribunal de Estrasburgo: ¿apuntalando los muros de la Europa fortaleza? Revista Española de Derecho Internacional, 72(2), 235-259. doi: 10.17103/redi.72.2.2020.1b.03.

Sánchez Tomás, J. M. (2018). Las “devoluciones en caliente” en el Tribunal Europeo de Derechos Humanos (STEDH, AS. N. D. y N. T. vs. España, de 03-10-2017). Revista Espanola de Derecho Europeo, 65, 101-135.

Soler García, C. (2018). La prohibición de las expulsiones colectivas de extranjeros en la jurisprudencia del Tribunal Europeo de Derechos Humanos. Revista General de Derecho Europeo, 45, 107-160.

Torrecuadrada García-Lozano, S. (2018). Los derechos humanos como límite a la gestión de los flujos migratorios mixtos. Revista Electrónica de Estudios Internacionales, 36, 1-25.

Tribunal Constitucional (2020). Nota informativa 108/2020. El Pleno del $T C$ avala la constitucionalidad de la Ley de protección de la seguridad ciudadana de 2015 salvo las grabaciones "no autorizadas" al a Policía. Recuperado de: https://www.tribunalconstitucional.es/NotasDePrensaDocumentos/NP_2020_108/NOTA\%20INFORMATIVA\%20N\%C2\%BA\%20108-2020.pdf (última consulta: 24/11/2020)

Unidad de Prensa del Tribunal Europeo de Derechos Humanos (2020). Factsheet on collective expulsion of aliens. Estrasburgo: Consejo de Europa. Recuperado de: https://www.echr.coe.int/Documents/FS_Collective_expulsions_ENG.pdfúltima consulta 21/03/2020) (última consulta: 21/03/2020)

Üstübici, A., \& İçduygu, A. (2018). Border closures and the externalization of immigration controls in the Mediterranean: A comparative analysis of Morocco and Turkey. New Perspectives on Turkey, 59, 7-31. doi: 10.1017/npt.2018.21.

Val, E. (2020, Febrero 13). Estrasburgo rectifica y avala las devoluciones en caliente de migrantes en la valla de Melilla. La Vanguardia. Recuperado de: https://www.lavanguardia.com/politica/20200213/473532156015/tedh-avala-devoluciones-en-caliente-inmigrantes.html (última consulta: 28/02/2020) 


\section{Legislación}

\section{Ámbito internacional}

Convenio de Viena sobre el Derecho de los Tratados de 1969, adoptado el 23 de mayo de 1969, y en vigor desde el 27 de enero de 1980.

Convenio para la Protección de los Derechos Humanos y de las Libertades Fundamentales, hecho en Roma el 4 de noviembre de 1950, y en vigor desde el 3 de septiembre de 1953.

\section{Ámbito nacional}

Constitución española, promulgada el 27 de diciembre de 1978, y en vigor desde el 29 de diciembre del mismo año. Boletín Oficial del Estado n.o 311, de 29 de diciembre de 1978.

Ley Orgánica 4/2000, de 11 de enero, sobre derechos y libertades de los extranjeros en España y su integración social. Boletín Oficial del Estado n.o 10, de 12 de enero de 2000.

Reglamento de la Ley Orgánica 4/2000, sobre derechos y libertades de los extranjeros en España y su integración social. Boletín Oficial del Estado n.o 103, de 30 de abril de 2011.

\section{Jurisprudencia}

\section{Tribunal Europeo de Derechos Humanos}

Sentencia del Tribunal Europeo de Derechos Humanos (Pleno) sobre el asunto Soering contra Reino Unido, de 7 de julio de 1989 (demanda n.o 14038/88).

Sentencia del Tribunal Europeo de Derechos Humanos sobre el asunto Cruz Varas y otros c. Suecia, de 20 de marzo de 1991 (demanda n.o 46/1990/237/307).

Sentencia del Tribunal Europeo de Derechos Humanos (Sala) sobre el asunto Amuur contra Francia, de 25 de junio de 1996 (demanda n.o 19776/92).

Decisión de admisibilidad del Tribunal Europeo de Derechos Humanos (Sección tercera) sobre el asunto T. I. contra Reino Unido, de 7 de marzo de 2000 (demanda n.o 43844/98).

Sentencia del Tribunal Europeo de Derechos Humanos (Sección tercera) sobre el asunto Hilal contra Reino Unido, de 6 de marzo de 2001 (demanda n.o 45276/99).

Sentencia del Tribunal Europeo de Derechos Humanos (Sala) sobre el asunto Ahmed contra Austria, de 17 de diciembre de 2001 (demanda n.o 25964/94).

Sentencia del Tribunal Europeo de Derechos Humanos (Sección tercera) sobre el asunto Čonka contra Bélgica, de 5 de febrero de 2002 (demanda n.o 51564/99).

Sentencia del Tribunal Europeo de Derechos Humanos (antigua Sección segunda), sobre el asunto Shamayec y otros contra Georgia y Rusia, de 12 de abril de 2005 (demanda n.. 36378/02). 
Decisión de admisibilidad del Tribunal Europeo de Derechos Humanos (Sección quinta), sobre el asunto Dzavit Berisha y Baljie Haljiti contra la Antigua República Yugoslava de Macedonia, de 16 de junio de 2005 (demanda n.o 18670/03).

Sentencia del Tribunal Europeo de Derechos Humanos (Sección tercera) sobre el asunto Salah Sheekh contra Países Bajos, de 11 de enero de 2007 (demanda n. 1948/04).

Sentencia del Tribunal Europeo de Derechos Humanos (Sección tercera) sobre el asunto Sultani contra Francia, de 20 de septiembre de 2007 (demanda n. 45223/05).

Sentencia del Tribunal Europeo de Derechos Humanos (Sección segunda), sobre el asunto Abdolkhani y Karimnia contra Turquía, de 22 de septiembre de 2009 (demanda n.․ 30471/08).

Sentencia del Tribunal Europeo de Derechos Humanos (Sección quinta) sobre el asunto Daoudi contra Francia, de 3 de diciembre de 2009 (demanda n.o 19576/08).

Sentencia del Tribunal Europeo de Derechos Humanos (Gran Sala) sobre el asunto M. S. S. contra Bélgica y Grecia, de 21 de enero de 2011 (demanda n.o 30696/09).

Decisión de admisibilidad del Tribunal Europeo de Derechos Humanos (Sección segunda) sobre el asunto Dritsas y otros contra Italia, de 1 de febrero de 2011 (demanda n.o 2344/02).

Sentencia del Tribunal Europeo de Derechos Humanos (Gran Sala) sobre el asunto Hirsi Jamaa y otros contra Italia, de 23 de febrero de 2012 (demanda n.o 27765/09).

Sentencia del Tribunal Europeo de Derechos Humanos (Sección cuarta) sobre el asunto M. A. contra Chipre, de 23 de julio de 2013 (demanda n.o 41872/10).

Sentencia del Tribunal Europeo de Derechos Humanos (Gran Sala) sobre el asunto F. G. contra Suecia, de 23 de marzo de 2016 (demanda n.o 43611/11).

Sentencia del Tribunal Europeo de Derechos Humanos (Gran Sala) sobre el asunto J. K. y otros contra Suecia, de 23 de agosto de 2016 (demanda n ํ59166/12).

Sentencia del Tribunal Europeo de Derechos Humanos (Gran Sala) sobre el asunto Khlaifia y otros contra Italia, de 15 de diciembre de 2016 (demanda n.o 16483/12).

Sentencia del Tribunal Europeo de Derechos Humanos (Sección tercera) sobre el asunto N. D. y N. T. contra España, de 3 de octubre de 2017 (demandas n.o 8675/15 y 8697/15).

Sentencia del Tribunal Europeo de Derechos Humanos (Sección cuarta) sobre el asunto M. A. y otros c. Lituania, de 11 de diciembre de 2018 (demanda n.o 59793/17).

Sentencia del Tribunal Europeo de Derechos Humanos (Gran Sala) sobre el asunto N. D. y N. T. contra España, de 13 de febrero de 2020 (demandas n.o 8675/15 y 8697/15).

\section{Tribunal Constitucional}

Sentencia 21/1997, de 10 de febrero, del Tribunal Constitucional. Boletín Oficial del Estado n.o 63, de 14 de marzo de 1997 (ECLI:ES:TC:1997:21). 
Sentencia 95/2003, de 22 de mayo, del Tribunal Constitucional. Boletín Oficial del Estado n.o 139, de 10 de junio de 2003 (ECLI:ES:TC:2003:95).

Sentencia 236/2007, de 7 de noviembre, del Tribunal Constitucional. Boletín Oficial del Estado n.o 295, de 10 de diciembre de 2007 (ECLI:ES:TC:2007:236).

Sentencia 17/2013, de 31 de enero, del Tribunal Constitucional. Boletín Oficial del Estado n.o 49, de 26 de febrero de 2013 (ECLI:ES:TC:2013:17). 